\title{
Extracellular deposition of matrilin-2 controls the timing of the myogenic program during muscle regeneration
}

\author{
Ferenc Deák ${ }^{1, *}$, Lajos Mátés ${ }^{1,2, *, \pm}$, Éva Korpos ${ }^{1,3, *}$, Ágnes Zvara ${ }^{2, *}$, Tibor Szénási ${ }^{2}$, Mónika Kiricsi ${ }^{4,5}$, \\ Luca Mendler ${ }^{4}$, Anikó Keller-Pintér ${ }^{4}$, Béla Ózsvári ${ }^{6}$, Hajnalka Juhász ${ }^{1}$, Lydia Sorokin ${ }^{3}$, László Dux ${ }^{4}$, \\ Nicolas Mermod ${ }^{7}$, László G. Puskás ${ }^{2,6}$ and Ibolya Kiss ${ }^{1,6, \pm}$
}

\begin{abstract}
Here, we identify a role for the matrilin-2 (Matn2) extracellular matrix protein in controlling the early stages of myogenic differentiation. We observed Matn2 deposition around proliferating, differentiating and fusing myoblasts in culture and during muscle regeneration in vivo. Silencing of Matn2 delayed the expression of the Cdk inhibitor p21 and of the myogenic genes Nfix, MyoD and Myog, explaining the retarded cell cycle exit and myoblast differentiation. Rescue of Matn2 expression restored differentiation and the expression of p21 and of the myogenic genes. TGF- $\beta 1$ inhibited myogenic differentiation at least in part by repressing Matn2 expression, which inhibited the onset of a positive-feedback loop whereby Matn2 and Nfix activate the expression of one another and activate myoblast differentiation. In vivo, myoblast cell cycle arrest and muscle regeneration was delayed in Matn2 ${ }^{-/-}$relative to wild-type mice. The expression levels of $\operatorname{Trf3}$ and myogenic genes were robustly reduced in Matn2 ${ }^{-/}$fetal limbs and in differentiating primary myoblast cultures, establishing Matn2 as a key modulator of the regulatory cascade that initiates terminal myogenic differentiation. Our data thus identify Matn2 as a crucial component of a genetic switch that modulates the onset of tissue repair.
\end{abstract}

KEY WORDS: Muscle regeneration, Myogenesis, Matn2 shRNA, TGF- $\beta$ signaling, BMP signaling, NFI, Trf3

\section{INTRODUCTION}

Skeletal muscle regeneration following injury is a multistep process that restores the tissue architecture by the sequential activation of multiple signaling pathways (Chargé and Rudnicki, 2004; Wagers and Conboy, 2005; Yin et al., 2013). The early degenerative phase involves inflammation, necrosis of the injured

${ }^{1}$ Institute of Biochemistry, Biological Research Centre, Hungarian Academy of Sciences, Szeged, H-6701 Szeged, Hungary. ${ }^{2}$ Institute of Genetics, Biological Research Centre, Hungarian Academy of Sciences, Szeged, H-6701 Szeged, Hungary. ${ }^{3}$ Institute of Physiological Chemistry and Pathobiochemistry, Muenster University, D-48149 Muenster, Germany. ${ }^{4}$ Institute of Biochemistry, Faculty of

General Medicine, University of Szeged, H-6720 Szeged, Hungary. ${ }^{5}$ Department of Biochemistry and Molecular Biology, Faculty of Natural Sciences and

Informatics, University of Szeged, H-6720 Szeged, Hungary. ${ }^{6}$ Avidin Ltd., H-6726

Szeged, Hungary. ${ }^{7}$ Institute of Biotechnology, University of Lausanne, and Center

for Biotechnology of the University of Lausanne and École Polytechnique

Fédérale de Lausanne, CH-1015 Lausanne, Switzerland.

*These authors contributed equally to this work

‡Authors for correspondence (mates@brc.hu; kiss@brc.hu)

This is an Open Access article distributed under the terms of the Creative Commons Attribution License (http://creativecommons.org/licenses/by/3.0), which permits unrestricted use, distribution and reproduction in any medium provided that the original work is properly attributed.

Received 25 August 2013; Accepted 8 May 2014 myofibers and degeneration of motor endplates, leading to denervation. The muscle is then repaired in four regeneration stages. Repair starts with the activation of satellite cells, which reside between the basement membrane and the sarcolemma of muscle fibers, to create a pool of proliferating myoblasts. This is followed by proliferation, differentiation and maturation stages, recapitulating the embryonic differentiation steps.

Muscle differentiation is directed by a conserved myogenic regulatory program during embryonic and fetal development and muscle regeneration (Chargé and Rudnicki, 2004; Shi and Garry, 2006). The proliferating myoblasts express the myogenic regulatory factors (MRFs) Myf5 and MyoD. MyoD initiates a complex muscle-specific gene expression program that also involves a network of other transcription factors committing myogenic precursors to differentiate (Aziz et al., 2010; Yokoyama and Asahara, 2011). This is accompanied by a switch of the core transcription machinery, as the MyoDdependent activation of the myogenin gene (Myog) requires the replacement of TFIID with the TRF3-TAF3 complex (Deato and Tjian, 2007, Deato et al., 2008). The expression of Myog and Mrf4 in committed myoblasts leads to the upregulation of the Cdk inhibitor p21 and to irreversible cell cycle exit (Walsh and Perlman, 1997). Subsequently, overt differentiation starts with the expression of muscle-specific contractile proteins, and the cells either fuse to form primitive multinucleated myotubes or merge with existing myofibers.

The myogenic program is fine-tuned during embryonic and fetal development and during muscle regeneration by morphogenetic regulation in response to inductive signals of growth factors (e.g. FGF, IGF and TGF- $\beta$ ), cytokines and various stimuli from the extracellular matrix (ECM) (Chargé and Rudnicki, 2004; Wagers and Conboy, 2005). TGF- $\beta$ family members inhibit muscle differentiation and growth following receptor binding and the initiation of specific intracellular signals by Smad2 and Smad3 proteins, whereas BMP signaling through Smad1, Smad5 and Smad8 is a positive regulator of muscle growth (Gardner et al., 2011; Sartori et al., 2009; Sartori et al., 2013; Winbanks et al., 2013). Recent data have also implicated specific members of the nuclear factor I (NFI/Nfi) family of transcription factors in muscle morphogenesis (Gronostajski, 2000), Nfia being responsible for the induction of embryonic muscle genes, whereas Nfix activates fetal genes (Messina et al., 2010).

The ECM has a variety of direct and indirect effects on muscle differentiation and regeneration. Importantly, the inhibition of ECM assembly interferes with myogenic differentiation independently of MRF expression (Osses and Brandan, 2002). During myoblast differentiation, the fibronectin-rich ECM is replaced by a laminin-211-containing basement membrane 
deposited by myotubes, which influences myogenic cell migration and differentiation, myofiber formation and innervation (Gullberg et al., 1998; Thorsteinsdóttir et al., 2011). A structurally and functionally specialized ECM mediates nervemuscle and muscle-tendon contacts at neuromuscular junctions (NMJ) and myotendinous junctions (MTJ), respectively (Sanes, 2003). Although ample evidence revealed a significant role for ECM components and cell-ECM interactions at all stages of muscle development (Thorsteinsdóttir et al., 2011), how distinct ECM components might contribute to skeletal muscle differentiation and regeneration remains largely unknown.

Microarray analysis has shown an increased expression of several ECM genes in a mouse model of muscle regeneration, including the matrilin-2 gene (Matn2) (Goetsch et al., 2003). Matn2 is the largest member of the matrilin family of multidomain adaptor proteins (Deák et al., 1997; Mátés et al., 2002). Matrilin oligomers interact with other ECM proteins to form filamentous networks by connecting collagen fibrils and proteoglycans (Deák et al., 1999; Klatt et al., 2011). Matn2 homo-oligomers are deposited in varying amounts in the uterus, heart, skeletal and smooth muscle, in loose and dense connective tissues, and they are associated with subepithelial basement membranes (Piecha et al., 1999). Recent studies have demonstrated that Matn2 is required for peripheral nerve regeneration (Malin et al., 2009), and that Matn2 regulation by the BMP7-Smad signaling pathway can modulate skin-wound healing (Ichikawa et al., 2008).

Here, we reveal transient Matn2 upregulation during notexininduced muscle regeneration in vivo and in differentiating myoblast cultures. We report delayed myogenic differentiation from Matn2-silenced myoblast cultures, and a mild dystrophy with delayed muscle regeneration in $\mathrm{Matn}^{-/-}$mice. We also establish that TGF- $\beta$ can inhibit C2 myoblast differentiation by decreasing Matn 2 expression, and lack of Matn2 delays the onset of Trf3, Nfix and MRF gene expression. Overall, our data implicate Matn2 in a signaling network controlling the onset of the myogenic program, thereby linking ECM-cell interactions to tissue differentiation and repair.

\section{RESULTS}

\section{Transient Matn2 upregulation during skeletal muscle regeneration}

We first assessed a potential role for Matn2 in muscle regeneration using the well-established model of notexin-induced rat soleus regeneration. Changes in the injected soleus weight over time reflected the expected progress of inflammation, necrosis and repair processes (Fig. 1A). Northern analysis showed marked Matn2 upregulation until 4 days after treatment, followed by a decline in its expression (Fig. 1B). The transient mRNA accumulation partially overlapped the expression profiles of the MyoD and Myog myogenic differentiation markers, but differed from the induction kinetics of other ECM components, such as biglycan (Bgn) and syndecan-4 (Sdc4). Quantitative RT-PCR (QRT-PCR) analysis of Matn2 mRNA revealed a 6.5-fold transient activation that followed the peak of expression of $M y o D$ and closely paralleled that of $M y o g$ (Fig. 1C). The Matn 2 mRNA level increased similarly to that of Fak (also known as Ptk2), a common integrin target (Goody and Henry, 2010). We concluded that Matn2 is upregulated during the regeneration phase, which involves myoblast proliferation and differentiation to myocytes, early myotubes and myofibers, whereas it is downregulated during myofiber maturation.

Immunoblots revealed predominantly Matn2 oligomers of low signal intensity in the untreated control, whereas mainly Matn2

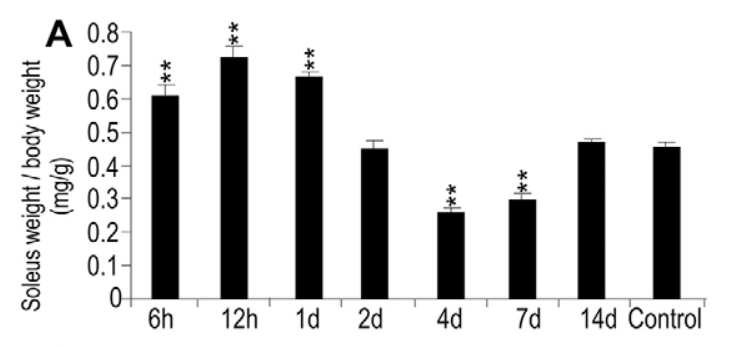

B
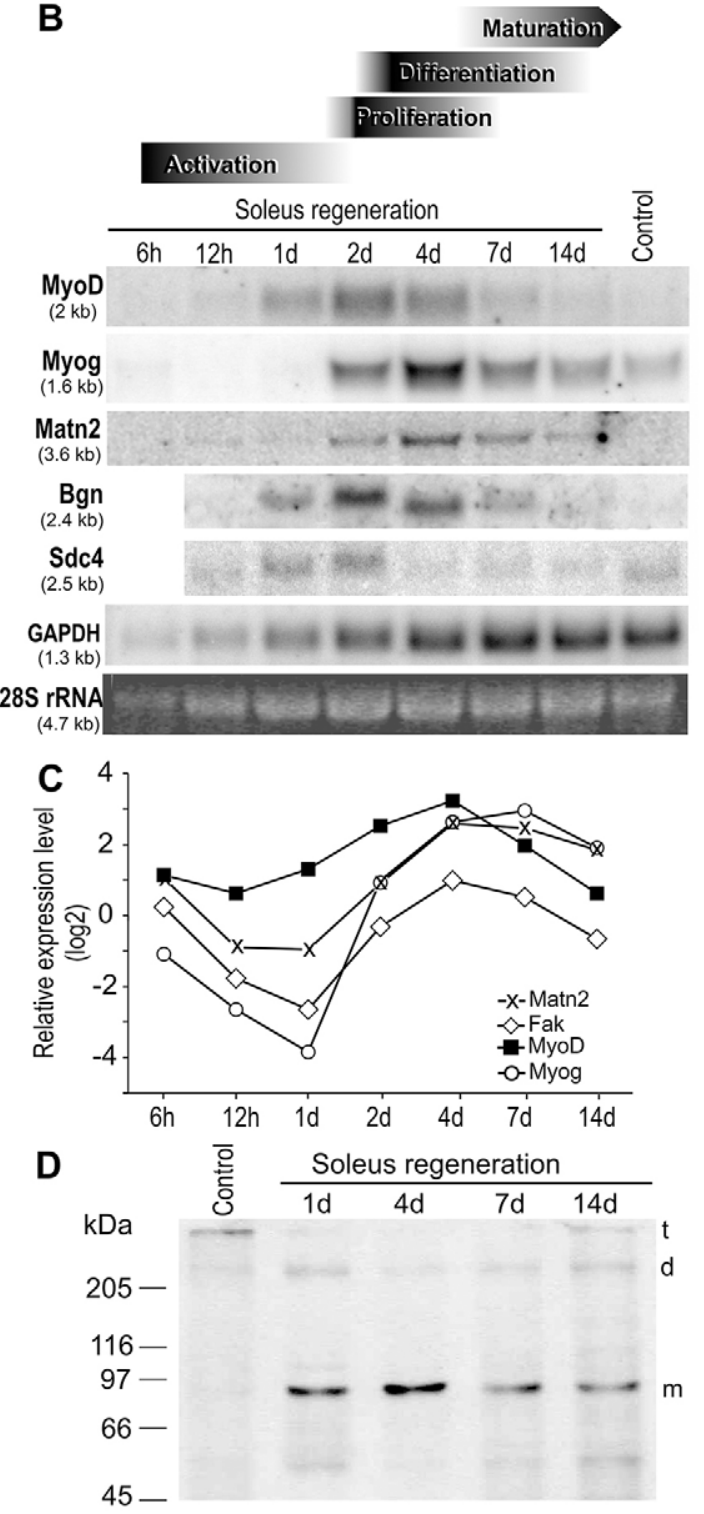

Fig. 1. Marker gene expression during rat soleus regeneration. (A) Weight changes during notexin-induced regeneration. Data show the mean \pm s.e.m. $(n \geq 3) ;{ }^{*} P<0.01$. $(\mathrm{B}, \mathrm{C})$ Kinetic changes in marker gene expression were aligned with the stage of regeneration (Shi and Garry, 2006), based on histological analysis of H\&E-stained sections (Fig. 2A). Pooled total RNA derived from control and regenerating samples $(n=3)$ was subjected to northern hybridization (B) and QRT-PCR using the SYBR green protocol (C). For QRT-PCR, relative expression levels normalized to those of the untreated control $\left(\Delta \Delta \mathrm{C}_{\mathrm{t}}\right)$ are shown.

(D) Immunoblot analysis of Matn2 expression during regeneration. $t$, trimer; d, dimer; m, monomer. 
monomers were observed during regeneration. The elevated monomer signal at 1 day post-injury likely resulted from the proteolytic cleavage of oligomers that might be poorly recognized by the antibody in the control (Fig. 1D). The amount of monomers decreased after day 4, whereas the oligomer formation was restored.

\section{Immunolocalization of Matn2 in regenerating muscles}

To reveal which cell types might express Matn2, we compared the localization of Matn2 with that of specific markers during known stages of muscle regeneration (Chargé and Rudnicki, 2004; Gorbe et al., 2005; Shi and Garry, 2006), which were determined by hematoxylin and eosin (H\&E) staining of muscle sections (Fig. 2; supplementary material Fig. S1). Unlike the weak Matn2 staining of the endomysium relative to nerves and blood vessels in the untreated muscle, an intense Matn2 signal was observed at the periphery of necrotic myofibers and in the interstitial tissue at day 1 post-injury (Fig. 2A-D; supplementary material Fig. S1A,D). This further implied a proteolytic release of Matn2 epitopes from oligomers and ECM linkages in the old endomysium, thereby resulting in better recognition by the antibody. Using myogenic, basement membrane and inflammatory cell markers, we observed Matn2 deposition around MyoD-, Myog- and Lama2-positive proliferating and differentiating myoblasts on day 2, but not around granulocytes and macrophages (Fig. 2B-F; supplementary material Fig. S1B,C; data not shown). Matn2 colocalized with laminin in the basement membrane surrounding desmin-positive fusing myoblasts, myotubes and myoblasts merging with newly formed myofibers (Fig. 2B-D,F), implying that both proteins can participate in the ECM assembly that assists myoblast differentiation and fusion. Matn2 signal was also relatively strong in the endomysium, but not in the laminin-containing basement membrane of recently formed myofibers strongly stained for desmin (Fig. 2B-D) but still containing central nuclei on day 14 (arrow, Fig. 2A). Matn2 expression decreased during myofiber maturation, but it was more intense and broader in the endomysium and interstitial tissue on day 14 than in the control (Fig. 2B-D). The Matn2 signal partially overlapped those of fibronectin and collagen-1 throughout the regeneration process (supplementary material Fig. S1D).

While keeping the muscle nerves intact, notexin treatment destroys their motor endplates. Unlike myoblast proliferation, myofiber maturation depends on nerve signals (Grubb et al., 1991; Sesodia and Cullen, 1991). Matn2 deposition was also highly elevated around nerves and the NMJs that were reestablished in large number between the recently formed myofibers and nerve terminals at days 4-7 (Fig. 2B,G). Double staining showed intense Matn2 deposition at re-established NMJs, specifically in close proximity to acetylcholine receptors in the postsynaptic membrane (Fig. 2H). The Matn2 signal extended to the synaptic membrane and the presynaptic area around the cap formed by terminal Schwann cells (TSCs) (Fig. 2I). The observed deposition of Matn2 around myoblasts, myotubes, newly formed myofibers and NMJs suggested a role for Matn2 in the early steps of myogenic differentiation and reinnervation.

\section{Transient Matn2 activation in differentiating C2 myoblasts}

To provide independent evidence that myoblasts can deposit a Matn2-rich ECM, we next monitored Matn2 expression in C2 myoblasts cultured in differentiation medium, as this cell line model was reported to faithfully mimic fetal muscle differentiation (Biressi et al., 2007; Halevy et al., 1995; Messina et al., 2010; Montarras et al., 1996). Polygonal C2 myoblasts proliferating in growth medium (day 0) showed Matn2, laminin and fibronectin deposition, but only traces of desmin and no $\alpha$-actinin immunofluorescence (Fig. 3A-D). In differentiation medium, myoblasts differentiated to spindle-shaped myocytes and myotubes exhibiting intense desmin, Matn2, laminin and fibronectin signal at day 2, followed by the formation of aligned multinucleated myotube-like structures with high desmin and laminin staining by day 6 (Fig. 3B,D). Long spindle-shaped cells staining for sarcomeric $\alpha$-actinin appeared in the culture from day 2 (Fig. 3C).

Whereas Matn2 was deposited by proliferating myoblasts in fine granules on day 0 , it formed laminin and fibronectin-connected filaments surrounding fusing myoblasts and primary myotubes from day 2 (Fig. 3D,E). The Matn2 filaments appeared to be involved in cell attachment (Fig. 3E), being incorporated into an extensive filamentous network closely associated with fibronectin and connected to the laminin-containing basement membrane around multinucleated myotubes by day 6 (Fig. 3D).

The Matn 2 mRNA level in differentiating myoblasts also exhibited a transient increase with a peak at day 2, thus overlapping the transient accumulation of $M y o D$ and $M y o g$ mRNAs (Fig. 3F). The amount of Matn2 trimers, dimers and monomers secreted into the medium also increased transiently to a maximum on days 2-4 in differentiation medium (Fig. 3G), concomitantly with the appearance of myotubes. These data thus confirmed the deposition of Matn2 by proliferating myoblasts and during the early steps of $\mathrm{C} 2$ myoblast differentiation.

\section{Matn2 is required for $\mathbf{C 2}$ myoblast differentiation}

To address whether Matn2 might be needed for myogenic differentiation, we silenced its expression in C2 myoblasts using an efficient transposon-based short-hairpin (sh)RNA expression system (Kaufman et al., 2005). Independent stable-knockdown lines constitutively expressing either Matn2-targeting shRNA (lines sh3, sh4 and sh7) or the control vector (line Ctrl) were established and tested for differentiation and the expression of marker genes. Matn2 mRNA levels were successfully reduced in lines $\mathrm{sh} 7, \mathrm{sh} 4$ and $\mathrm{sh} 3$, with expression levels ranging from $52.2 \%$ to $17.6 \%$ of that of the control line, as determined by QRT-PCR (Fig. 4A); expression of the Matn2 protein decreased similarly (supplementary material Fig. S2B). Prior to differentiation, the Matn2-silenced cells were morphologically identical to control myoblasts (data not shown) and proliferated at similar rates, as based on their mitochondrial activity (Fig. 4B) and on cell count data (data not shown). Upon culturing in differentiation medium, myotube formation was delayed by $2-$ 3 days and the frequency of sarcomeric $\alpha$-actinin-positive myocytes and their fusion to multinucleated myotubes was highly reduced in Matn2-silenced myoblast cultures relative to that of control cultures (supplementary material Fig. S2A,B). The primary myotube frequency, fusion index and differentiation index decreased in correlation with the reduction in Matn2 immunofluorescence and mRNA expression of the cultures (Fig. 4A,C; supplementary material Fig. S2B). Thus, silencing Matn2 expression delayed both the differentiation and fusion of myoblasts.

Delayed myoblast differentiation was further supported by comparative QRT-PCR, which revealed the most robust changes in myogenic gene expression between the control line and the sh4 and sh3 silenced cell lines in repeated differentiation experiments (supplementary material Fig. S2C; data not shown). Thus, Matn2 silencing interfered with the transient activation of $M y o D$ and 

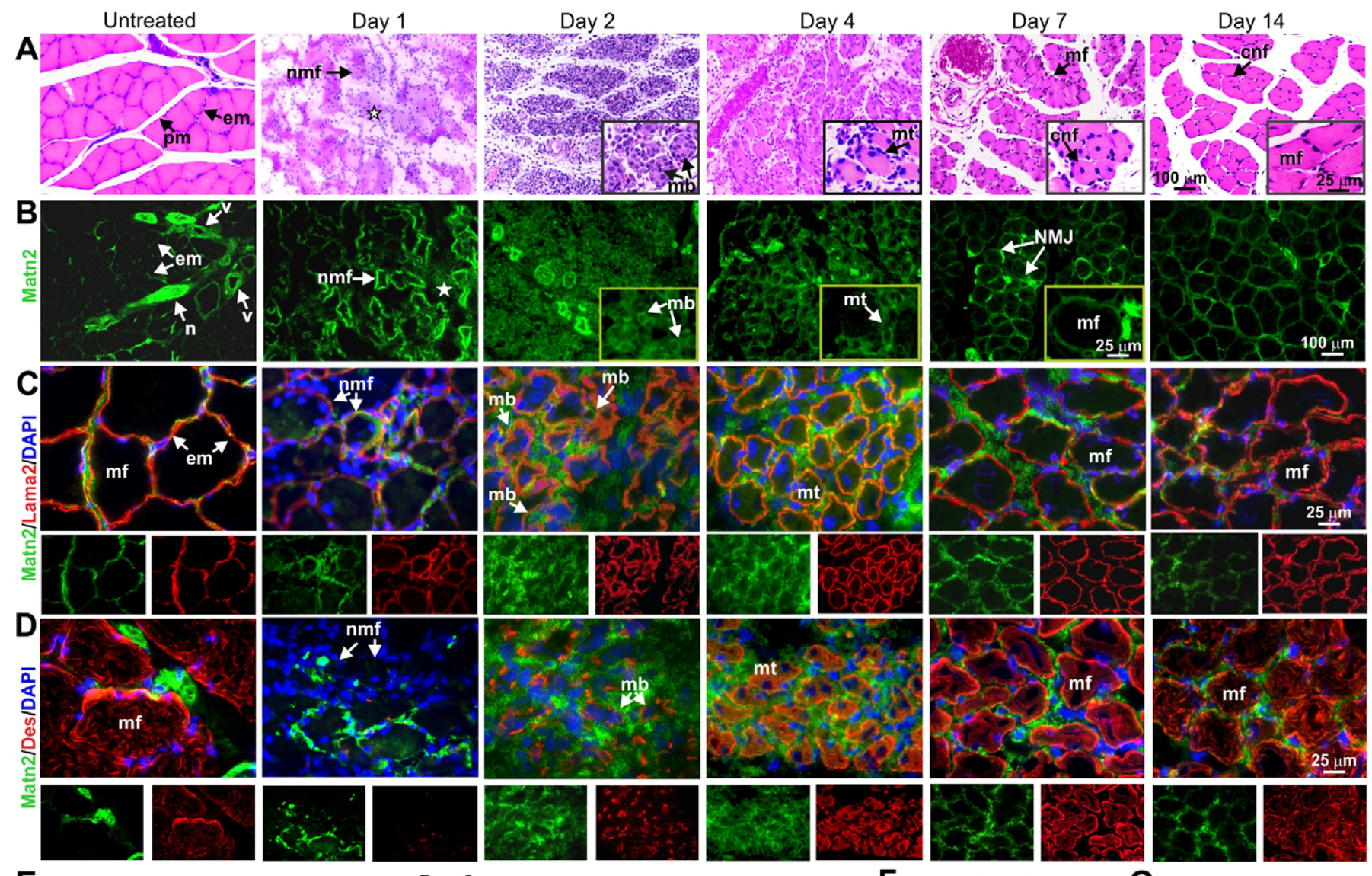
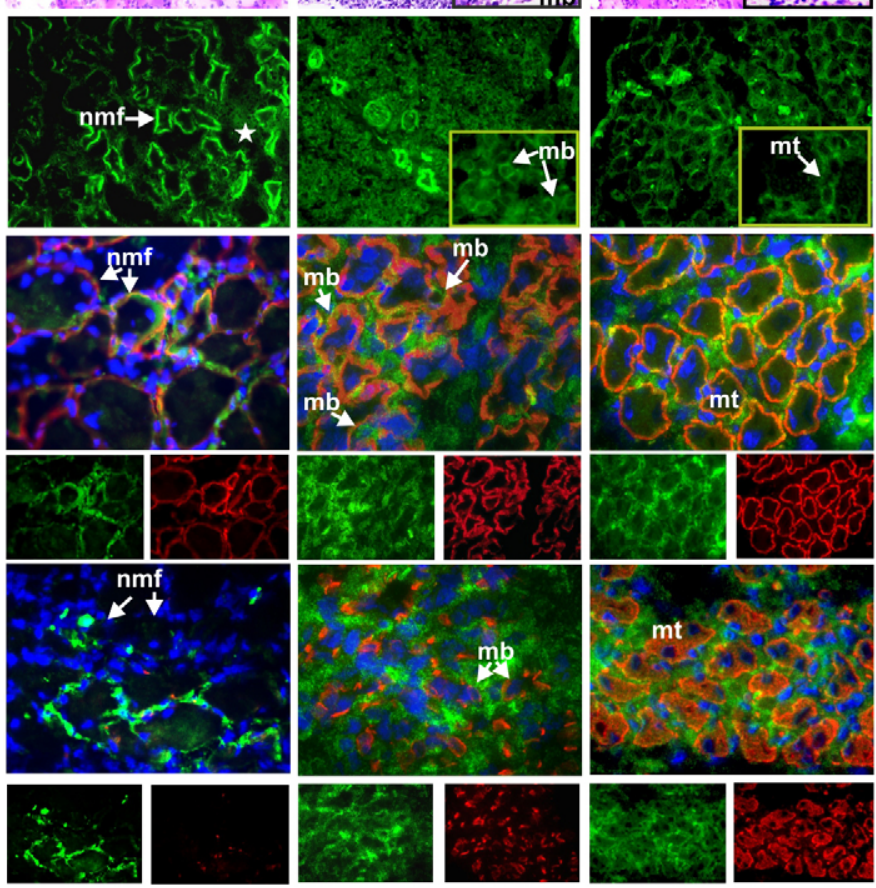

$\mathbf{F}$

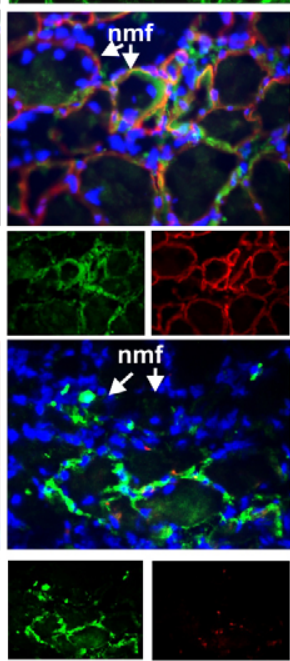

Day 2
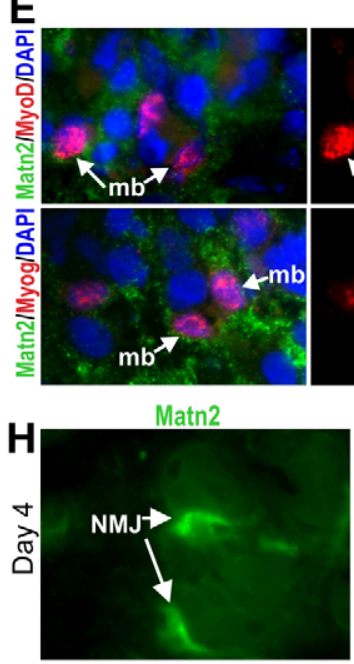

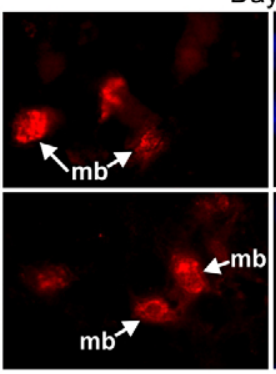

BTX

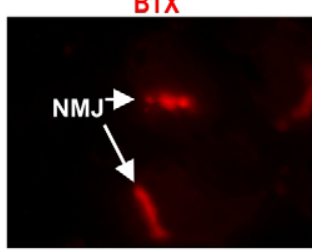

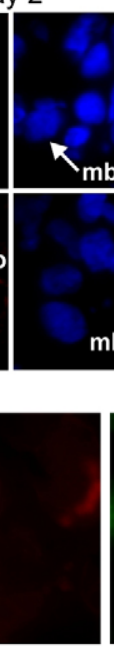
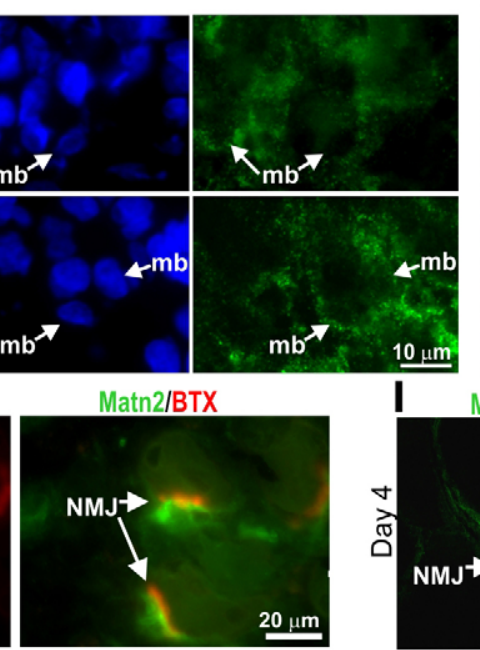

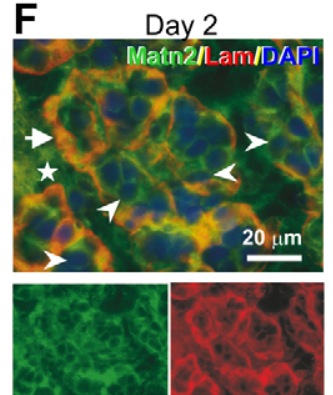

$\mathbf{G}$
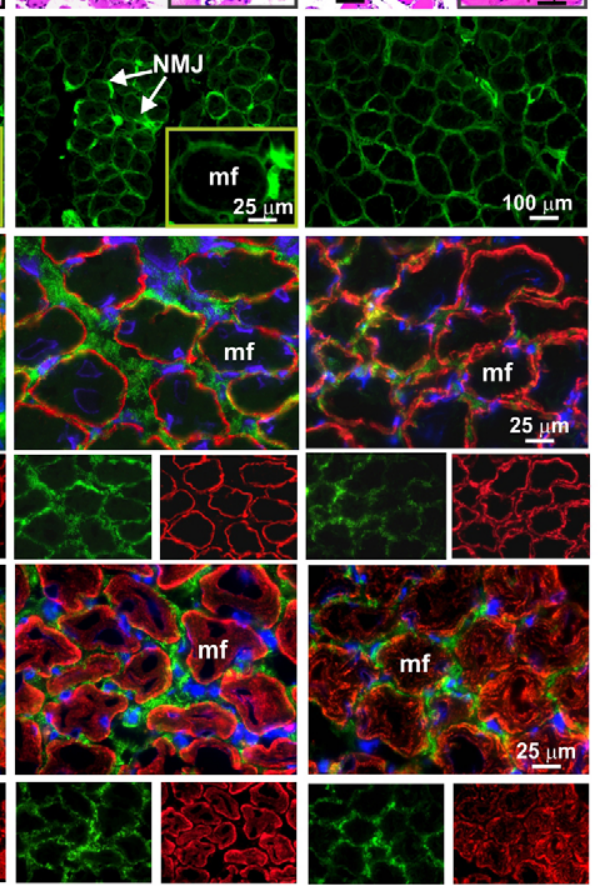

Day 4 Matn2/BTX
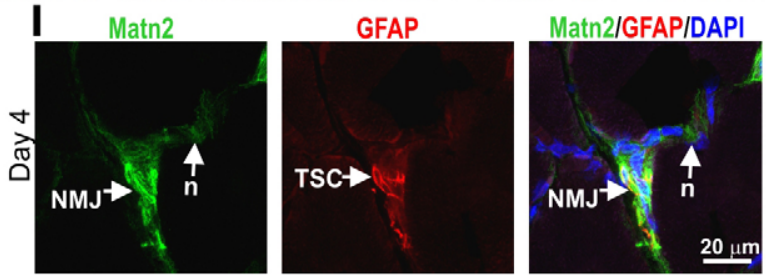

Fig. 2. Progress of morphological changes and Matn2 deposition during rat soleus regeneration. (A) H\&E staining of transverse paraffin sections. The star indicates inflammatory cells. (B-D) Immunofluorescence of serial cryosections for Matn2 (B-D) and laminin $\alpha 2$ (Lama2) (C) or desmin (Des) (D). The star indicates interstitial tissue (B). (E) Deposition of Matn2 around MyoD- and Myog-expressing proliferating and differentiating myoblasts at day 2 post-injury. (F) Matn2 deposition in the interstitial tissue (star) and around myoblasts (arrowhead) differentiating and fusing within the basement membrane, which is also stained for laminin-111 (Lam, arrow), at 2 days post-injury. (G-I) Localization of Matn2 to NMJs on day 4 . Note the strong Matn2 signal at the newly established NMJs, as visualized by Rhodamine-labeled $\alpha$-bungarotoxin (BTX) staining of acetylcholine receptors (G, arrowhead). There is partial overlap between Matn2 and $\alpha$-bungarotoxin signals at NMJs (H, arrows). TSCs visualized by GFAP staining are covered by Matn2-rich ECM at the NMJ (I). Insets show a section of the main image at higher magnification $(A, B)$. Single-channel images of the entire image $(C, D, F)$ or the outlined area $(G)$ are shown beneath the main image. cnf, centrally nucleated myofiber; em, endomysium; mb, myoblast; mf, myofiber; mt, myotube; $n$, nerve; nmf, necrotic myofiber; pm, perimysium; v, blood vessel. 


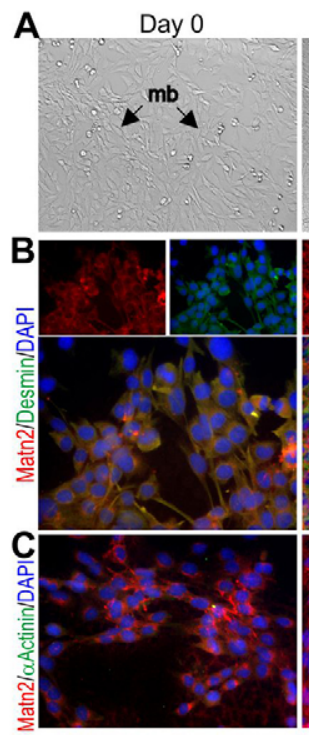

D
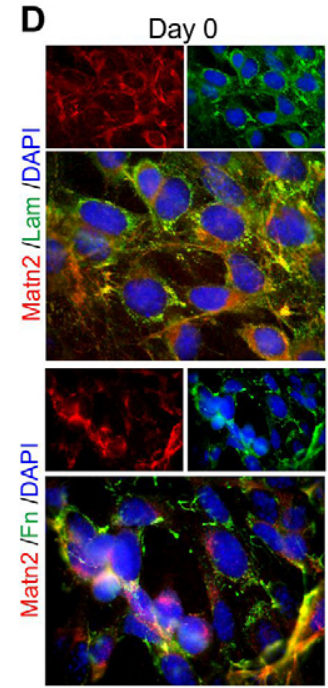

Day 2

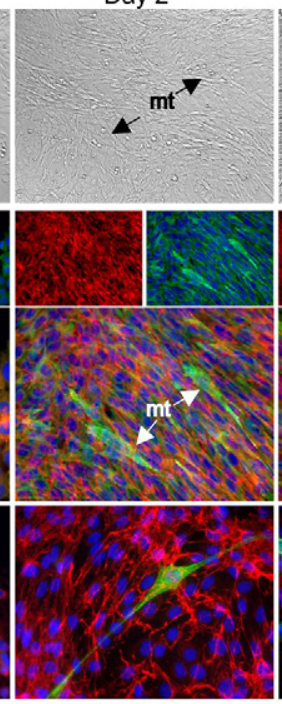

Day 2
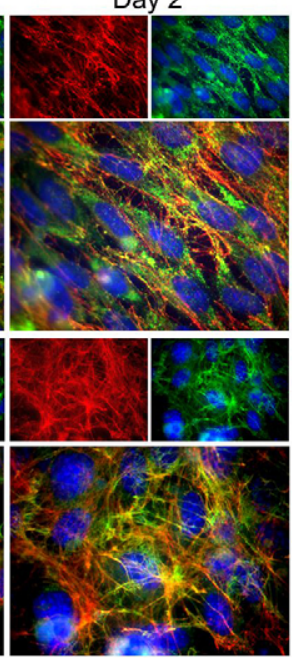

Day 4

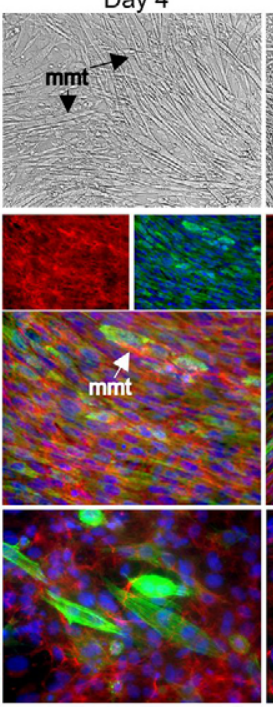

Day 6
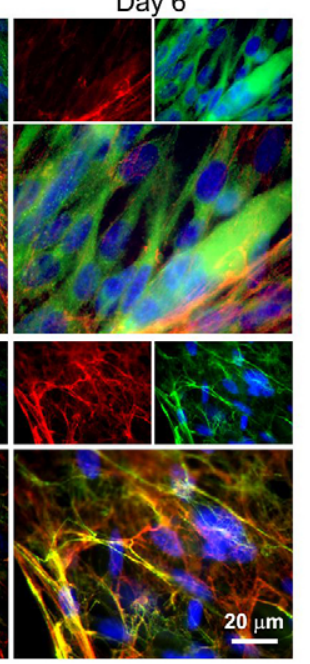

Day 6

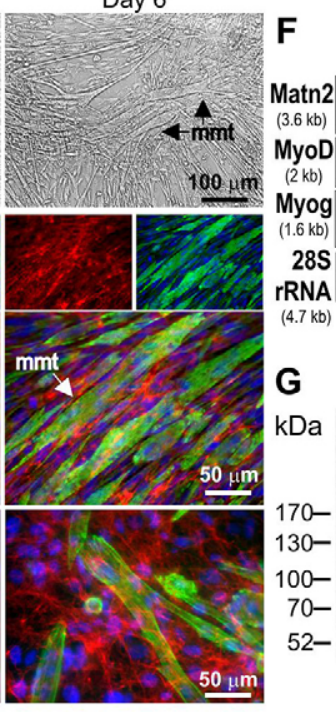

E Day 0 E Matn2/Vinculin/DAPI

$\begin{array}{lllllll}\text { d0 } & \text { d1 } & \text { d2 } & \text { d3 } & \text { d4 } & \text { d5 } & \text { d6 }\end{array}$

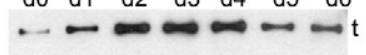

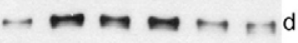

$\omega \omega \omega \omega \mathrm{m}$

70

$52-$

Day 4
Matn2/Paxillin/DAPI
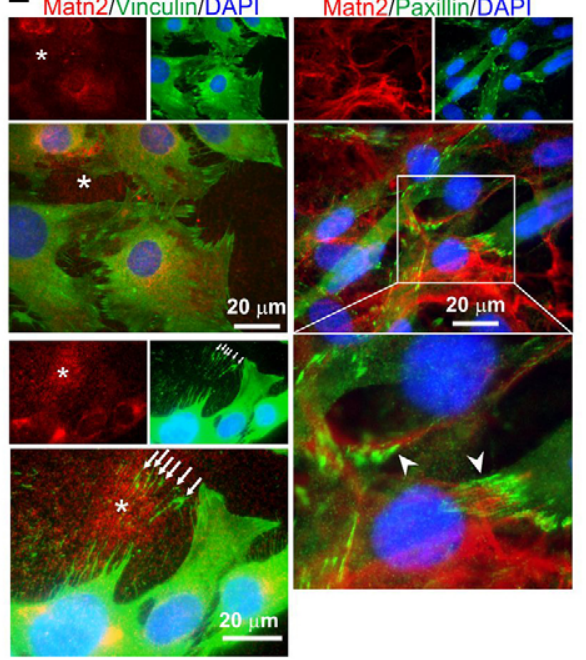

Fig. 3. Matn2 expression in proliferating and differentiating $\mathbf{C 2}$ myoblasts. (A-E) Phase-contrast images (A) and double immunofluorescence for Matn2 and other markers (B-E) of myoblast cultures differentiating to multinucleated myotubes (mmt) in differentiation medium. Desmin (B) and $\alpha$-actinin staining (C) demonstrates the progress of differentiation. mb, myoblast; mt, myotube. (D) Partial colocalization of Matn2 with laminin-111 (Lam) and fibronectin (Fn). (E) Granular Matn2 deposition (asterisk) by proliferating myoblasts (day 0). Arrows mark the vinculin-positive focal adhesions left behind upon cell movement. Matn2 filaments are linked to the cells at paxillin-positive focal adhesions (arrowhead) on day 4. Separate images for Matn2 alone or for other markers and DAPI are shown above the main images in $B, D$ and $E$. The area outlined in white in $E$ is shown at higher magnification below the main image. ( $F$ ) Comparison of mRNA levels for Matn2 and MRFs by northern hybridization. (G) Immunoblot analysis of Matn2 that was secreted daily into the differentiation medium. t, trimer; d, dimer; m, monomer.

Myog, as well as with the progressive increase in the p21 mRNA level observed in control myoblasts, readily explaining the delayed commitment, cell cycle exit and differentiation of the silenced cell lines. Matn2 silencing also hampered the activation of Fak, a gene encoding a modulator of cell-ECM contacts, and the transient rise in the expression of ECM genes (e.g. Lama2, Colbal and $S d c 4$ ), the expression of which paralleled that of Matn 2 in the control line. As no marked alteration was seen for the unrelated control p53 and Colla1 mRNAs, this indicated that Matn2 silencing exerts a specific effect on the expression of MRF and differentiation-related genes.

Next, we tested whether rescuing Matn2 synthesis in a silenced cell line can restore the proper timing of myogenic differentiation. To this end, we mutated the sequence targeted by the shRNA in the mouse Matn 2 cDNA in the third positions of codons, thereby preserving its protein-coding capacity while disrupting the shRNA target site (Fig. 4D). Then, we introduced a constitutive expression vector harboring the modified cDNA into Matn2-silenced sh3 myoblasts and selected for pools of puromycin-resistant stable clones (sh3-res2) for further analyses (Fig. 4E-I). The Matn2 levels of the complemented sh3-res2 myoblasts reached those of the control line in both the conditioned differentiation medium and in the filamentous ECM extracts (Fig. 4E,F). As expected, given the use of the constitutive CMV promoter to drive Matn2 expression, a decrease in Matn2 level was not noted in the sh3-res2 culture at day 6 in differentiation medium. During differentiation, $\alpha$-actinin-positive myotubes appeared at a frequency similar to that of the control line (Fig. 4G,H), and the myoblast proliferation rates were similar (data not shown). Bmp signaling, which controls muscle growth 
A

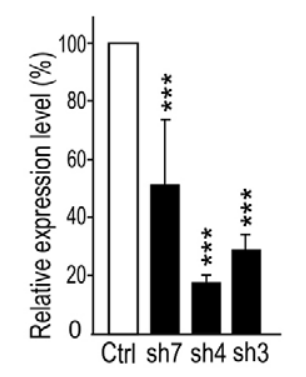

D

\section{short hairpin sequence}

. GCC ATT GAG GAA GAA CTA CttC

..CGG TAA CTC CTT CTT GAT Gaga

\section{Matn2 coding sequence}

..GCC ATT GAG GAA GAA CTA CAG GAG ATT

..Ala Ile Glu Glu Glu Leu Gln Glu Ile

\section{rescue cDNA sequence}

. Gca ATa GAa GAg GAg CTC CAG GAG ATT

. Ala Ile Glu Glu Glu Leu Gln Glu Ile
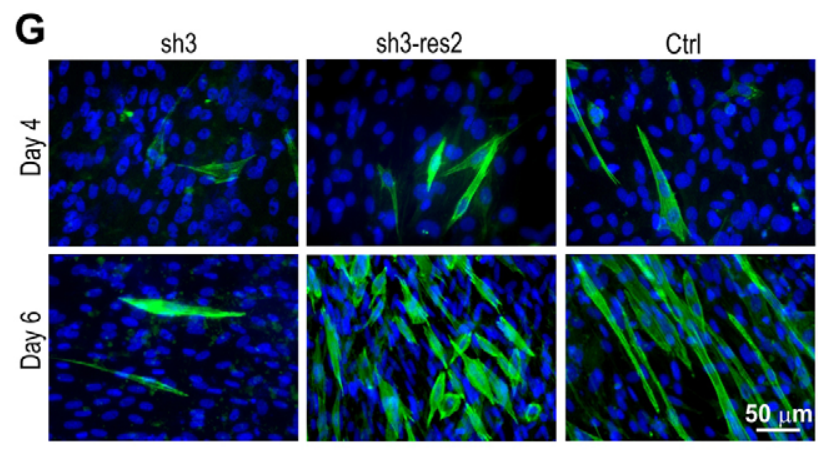

C
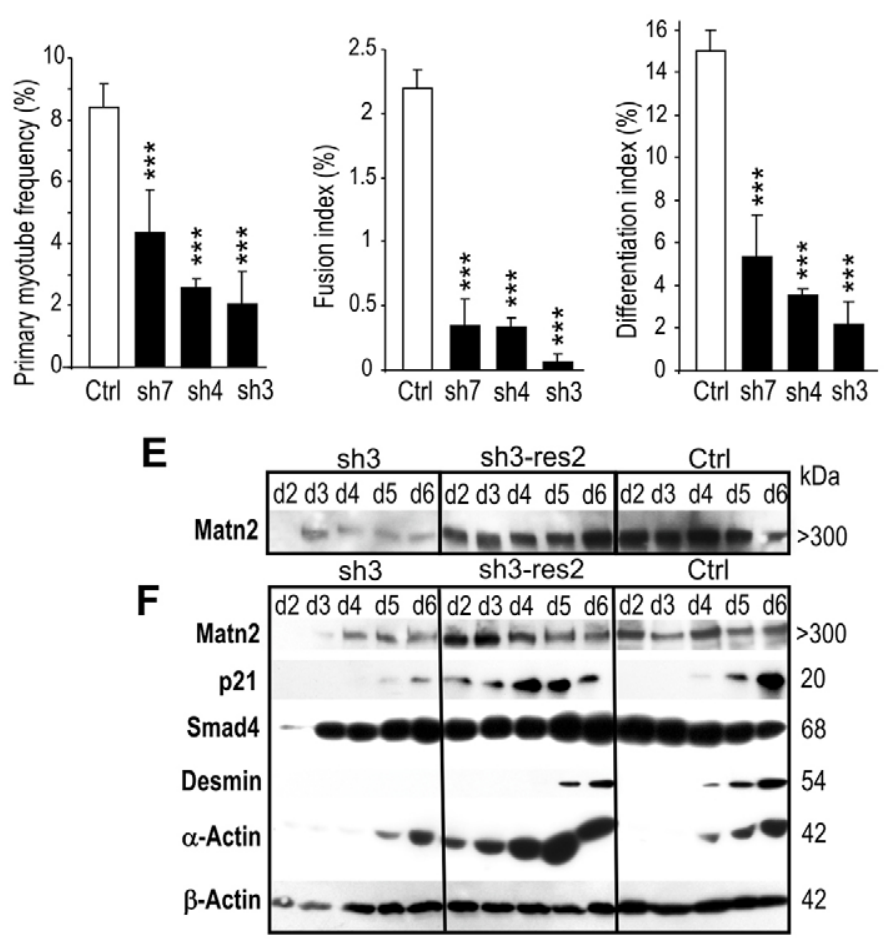

H

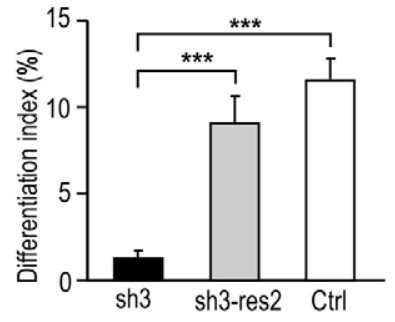

I
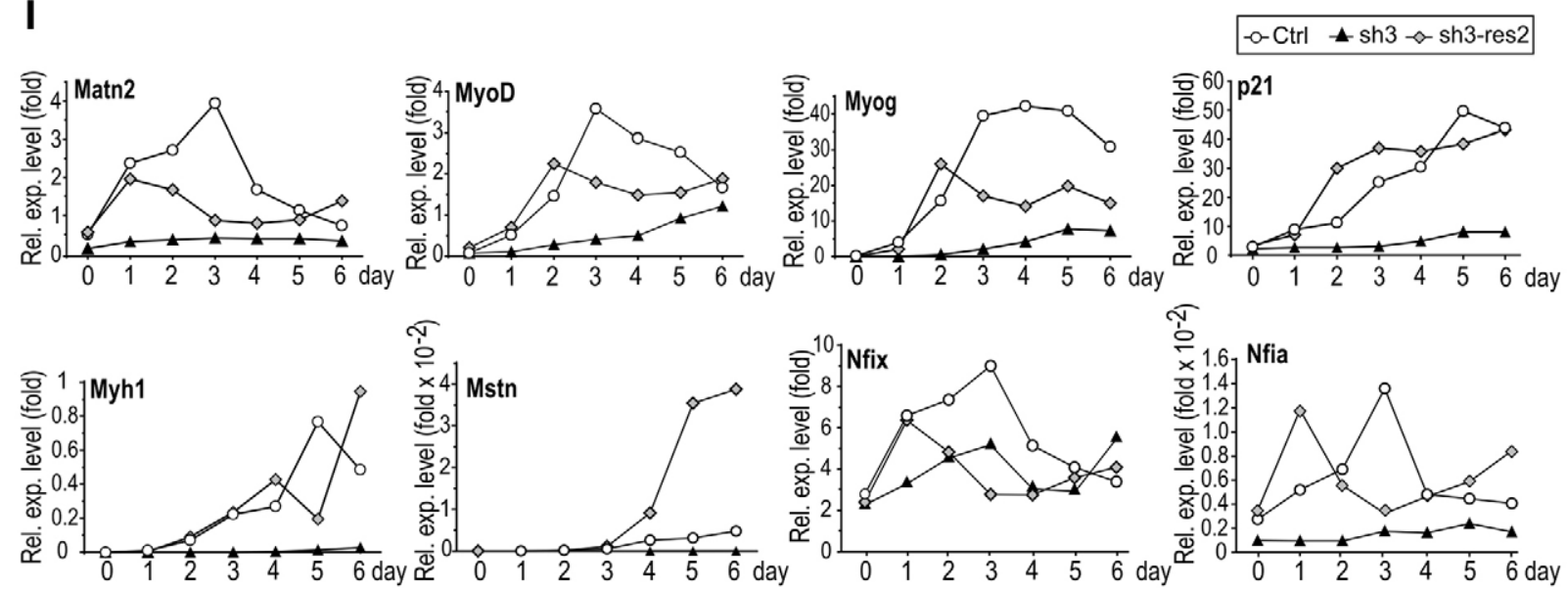

Fig. 4. The effect of Matn2 silencing and rescue on differentiation and marker gene expression of C2 myoblasts. (A) Matn2 mRNA levels were measured by QRT-PCR in proliferating C2 cell lines stably expressing Matn2 shRNA (sh7, sh4 and sh3) or the control vector (Ctrl). (B) The proliferation rate of the control and silenced cell lines was determined by using the MTS assay in growth medium. (C) Primary myotube frequency, fusion index and differentiation index of the cell lines on day 5 in differentiation medium. (D) Coding sequences are depicted for the Matn2 shRNA, the endogenous Matn2 and the rescue cDNA clone, which is resistant to shRNA interference. Immunoblotting was performed on the conditioned differentiation medium (E) and cell lysates $(F)$ from the silenced sh3,

rescued sh3-res2 and Ctrl myoblast cultures. Only the trimeric form of Matn2 is shown. Cytoskeletal $\beta$-actin served as a loading control. (G) Immunofluorescence for $\alpha$-actinin-positive cells in the cultures. (H) Differentiation index as determined on day 5. (I) QRT-PCR analysis of relative gene expression (Rel. exp.) in the same cultures using TaqMan probes. Marker mRNA levels are given as fold values relative to the Hprt mRNA level. Data show the mean $\pm s . e . m$. (A-C, H). ${ }^{* * *} P<0.001$, compared with control $(n=3-5)$. For $E-G$ and I, representative data from three independent experiments are shown. 
(Sartori et al., 2013; Winbanks et al., 2013), yielded comparable effects, as judged from the similar phosphorylation of Smad1/5/8 (supplementary material Fig. S3B). Smad4 expression was not altered, but large differences were seen in the expression of $\mathrm{p} 21$ (Fig. 4F). Unlike its low level in sh3 cells, p21 expression could already be detected at day 2 in the rescued culture, and it increased steadily to reach a level of expression similar to that of the control, but at an earlier time-point. Desmin and $\alpha$-actin expression was also rescued in the sh3-res2 cultures. As Matn2 silencing also altered the phosphorylation of Fak and p42/44 (also known as Erk1/2) (supplementary material Fig. S3B,C), it is likely to modulate several signaling pathways. Thus, the decreased expression of Matn2 hampered the induction of $\mathrm{p} 21$ and overt differentiation, despite the increased expression of the TGF- $\beta$ signaling intermediate Smad4, and this effect could be reversed by restoring Matn2 expression and its deposition in the ECM. QRT-PCR confirmed the restoration of muscle-specific gene expression in differentiating Matn2-rescued myoblasts (Fig. 4I), and the increase in the Matn2 level was paralleled by the increased expression of $M y o D$ and $M y o g$ and of the adult myosin heavy chain (Myhl) mRNAs.

The finding that Matn2 expression might regulate myoblast differentiation prompted us to assess the regulation of transcription factors that are possibly involved in the onset of Matn2 expression. Nfi proteins have been implicated in the control of adult stem cells and tissue regeneration in connection with TGF- $\beta$ signaling (Plasari et al., 2009; Plasari et al., 2010). Nfix has been shown to drive a transcriptional switch from embryonic to fetal myogenesis in vivo and in $\mathrm{C} 2$ culture by suppressing the effect of Nfia and activating fetal muscle genes (Messina et al., 2010). When monitoring Nfix or Nfia expression during myogenesis, we observed that Nfix and, to lesser degree, Nfia were indeed activated in both the differentiating control and Matn2-rescued myoblasts, but were either silent or only expressed at low levels in the silenced cells (Fig. 4I). The Nfix, Nfia and Matn2 mRNAs accumulated with similar kinetics in Matn2-expressing cells, and their expression preceded myogenic gene expression. This suggested that Matn2 might control myogenic differentiation by regulating the expression of $\mathrm{Nfi}$ proteins. Interestingly, a rise in Matn2 expression above a threshold level was likely needed to turn on the expression of Nfix and of the downstream Myh1 and Mstn genes in sh3-res2 cultures (compare Fig. 4I and supplementary material Fig. S3A), implying that Matn2 and Nfix might be part of a genetic switch driving an all-or-none differentiation response.

\section{TGF- $\beta$ signaling represses Matn2 expression and myoblast differentiation}

Matn 2 has been shown to be regulated by Smad signaling in other cell types (Ichikawa et al., 2008), and TGF- $\beta$ and Smad2/3 signaling is known to inhibit myogenic differentiation and muscle growth (Gardner et al., 2011; Sartori et al., 2009; Winbanks et al., 2012). Thus, we next assessed whether Matn2 and TGF- $\beta$ signaling might regulate one another in differentiating myoblasts. As expected, the addition of TGF- $\beta 1$ to differentiation medium inhibited the differentiation of the control line and hampered Smad1/5/8 phosphorylation (Fig. 5A,B). However, TGF- $\beta 1$ had only a small delaying effect on the differentiation of sh3 myoblasts, whereas Matn2 expression rescue restored the inhibition (Fig. 5A). TGF- $\beta 1$ robustly inhibited the increase in Matn 2 mRNA levels, and it consistently reduced the deposition of Matn2 in the ECM from the control and sh3-res2 cultures, especially during the early stages of differentiation (12-36 h, Fig. 5C,D). Similarly, TGF- $\beta 1$ further reduced the low levels of Matn 2 mRNA and of high-molecular-mass Matn2 complexes from differentiating sh3 myoblasts. Interestingly, the decrease in the p21, Trf3, Nfix and Nfia mRNA levels paralleled the decreased Matn2 expression, whereas both TGF- $\beta 1$ and differentiation medium strongly induced Smad4 expression (Fig. 5C,D). The most prominent decrease in p21 expression was obtained in the TGF- $\beta 1$-treated sh3 cells, which displayed the lowest Matn2 levels and the highest Smad4 levels. As Trf3 is needed for the transition of the basal transcription machinery and for MyoD-dependent Myog induction during myogenesis (Deato and Tjian, 2007; Deato et al., 2008), and both Matn2 silencing and TGF- $\beta 1$ compromised Trf3 induction in differentiation medium, our data suggest that low extracellular Matn2 and TGF- $\beta 1$ signaling act in concert to inhibit p21 expression and myoblast differentiation. Accordingly, TGF- $\beta 1$ abolished the induction of $\operatorname{Trf} 3$ and subsequently reduced $M y o D$ and $M y o g$ induction upon differentiation of Matn2-expressing control and sh3-res2 myoblasts, whereas TGF- $\beta 1$ further reduced the silenced Matn2 level and fully abrogated the expression of the two MRFs from sh3 cells (Fig. 5D). Overall, we concluded that Matn2 can activate $\operatorname{Trf} 3$ and $\mathrm{p} 21$ expression and myogenic differentiation, and the TGF- $\beta 1$-Smad-pathway-mediated inhibition of differentiation might stem in part from the inhibition of Matn2, Trf3, p21 and perhaps also Nfix expression.

Matn2 is activated by the myogenic Nfix and MyoD regulators Based on the observation that Matn2 and Nfix mRNAs accumulated with comparable kinetics during early myogenesis and on the previous finding that Nfix can promote myogenesis, we next assessed whether Nfix might directly regulate Matn2 expression. As Matn2 is transcribed from two promoters (Mátés et al., 2002), we tested which of the upstream $\left(\mathrm{P}_{\mathrm{u}}\right)$ or downstream promoter $\left(\mathrm{P}_{\mathrm{d}}\right)$ can direct the transient gene activation during muscle regeneration and myoblast differentiation (Fig. 6A-C). Transcription from $\mathrm{P}_{\mathrm{u}}$ did not change markedly in either case. By contrast, the $\mathrm{P}_{\mathrm{d}}$-specific transcript was reproducibly upregulated between $6 \mathrm{~h}$ and 4 days after soleus injury, followed by a decline during myofiber formation (Fig. 6B, arrow). Consistently, transcription from $\mathrm{P}_{\mathrm{d}}$ increased transiently during the early stages of $\mathrm{C} 2$ myoblast differentiation, but ceased during the formation of multinucleated myotubes (Fig. 6C, arrow).

Sequence analysis revealed putative NFI- and MyoD-binding motifs in the $\mathrm{P}_{\mathrm{d}}$ region, including potentially overlapping binding sites for both proteins (Fig. 6D). Electrophoretic mobility shift assay (EMSA) showed MyoD binding to the Pd-12/+15 DNA element near the transcription start site, and this binding was abolished by mutation in the MyoD motif (Mdm1) (Fig. 6D,F). Both MyoD and the CTF1 NFI isoform bound weakly to the $\mathrm{Pd}-135 /-107$ upstream element, and point mutations disrupting both consensus motifs (NfMdm1) abolished this interaction. Low amounts of MyoD inhibited NFI binding, indicating that the two proteins can compete for binding to the distal overlapping sites. The Mdm1 mutation moderately increased the $P_{d}$ activity in $C 2$ myoblasts (Fig. 6E,G). An NFI-contact-point mutation (Nfm1) in the overlapping NFI and MyoD sites was strongly inhibitory, whereas the NfMdm1 mutation that eliminated the binding of both proteins increased the promoter activity. In C2 myoblasts, MyoD expression decreased whereas Nfix expression increased the $\mathrm{P}_{\mathrm{d}}$-driven luciferase activity (Fig. 6H). Nfix expression in COS-7 cells confirmed that it acts as an activator of the $\mathrm{P}_{\mathrm{d}}$, as did 
A

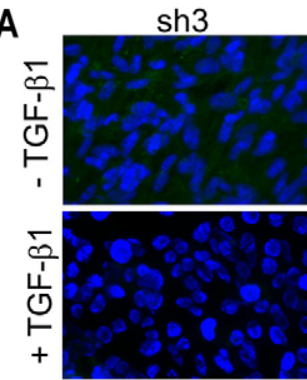

sh3-res2

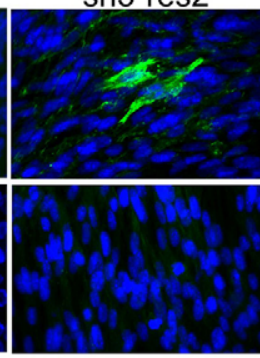

C trl
Ctrl

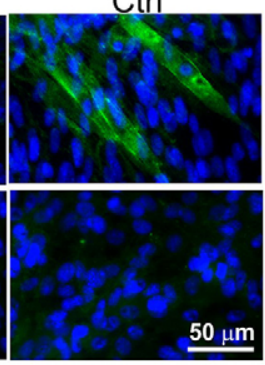

B

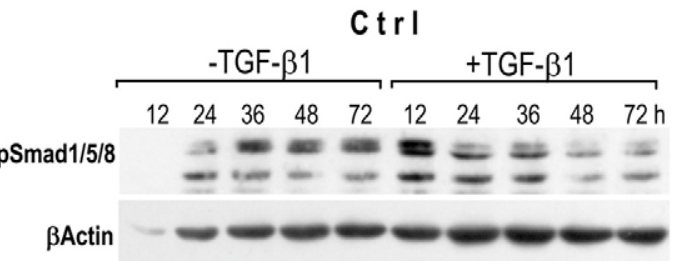

sh 3 - res 2

sh 3

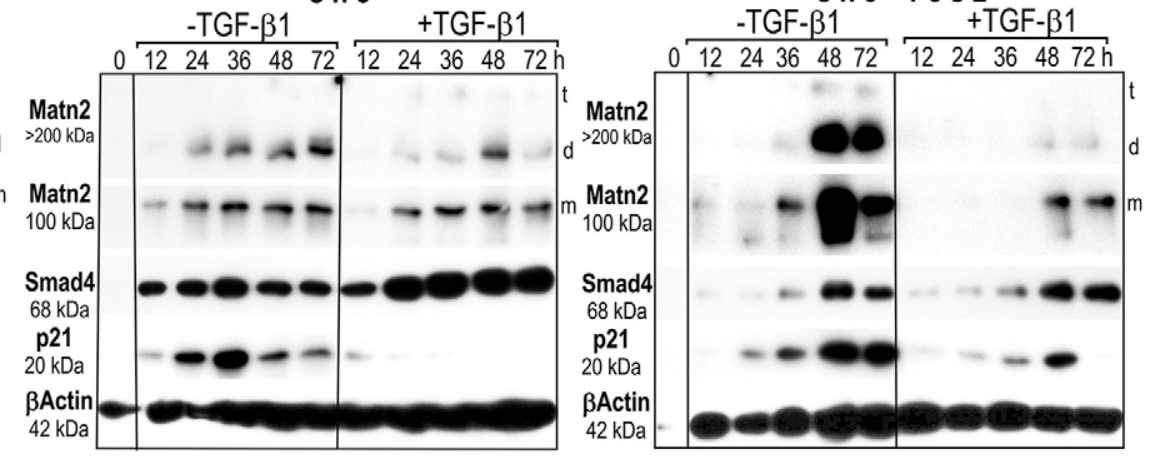

D 0.3 Matn2
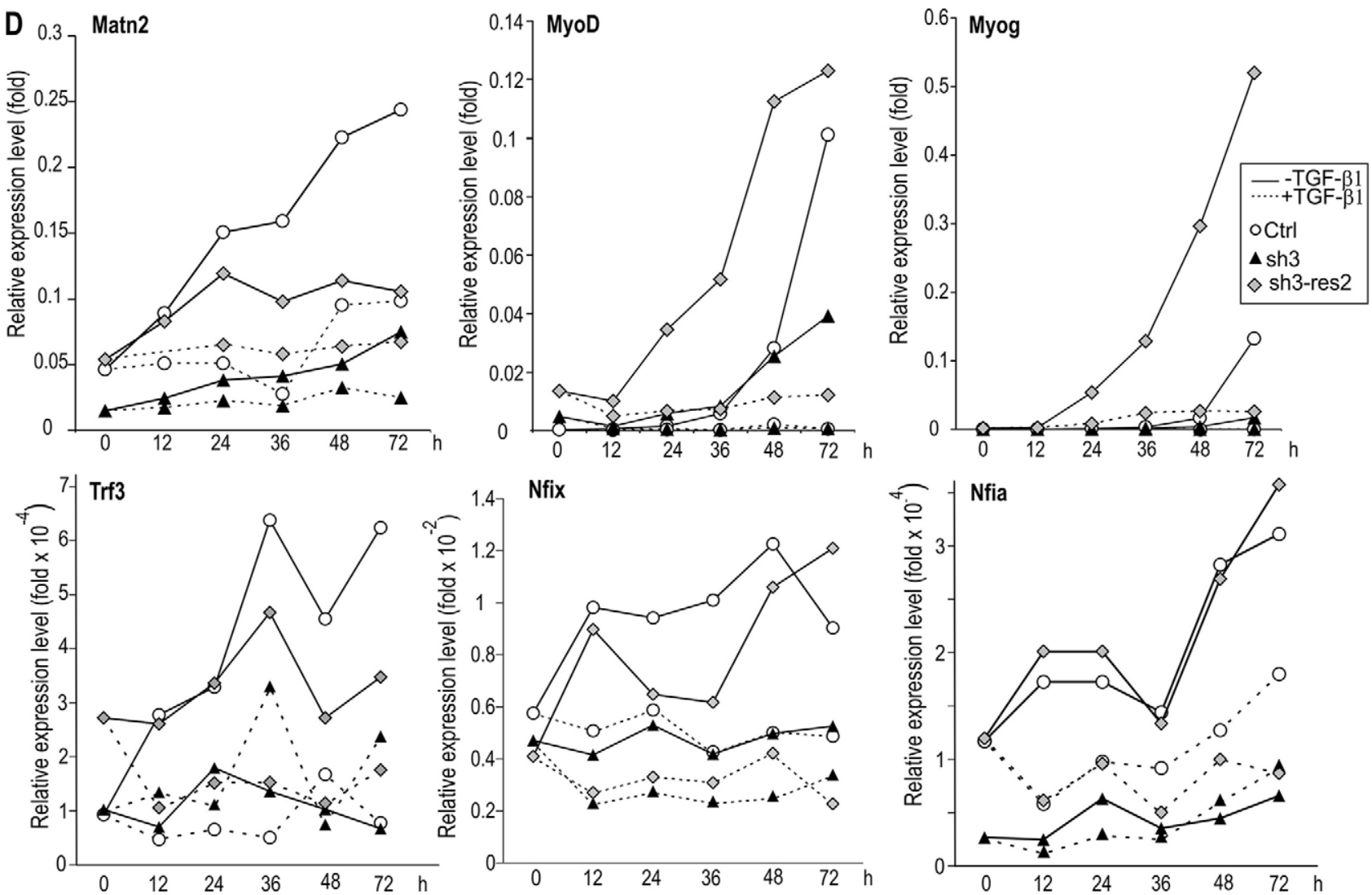

Fig. 5. The effect of TGF- $\beta 1$ on the differentiation of Ctrl, sh3 and sh3-res2 myoblasts. Cells were cultured in differentiation medium with and without TGF$\beta 1$. (A) Immunofluorescent staining for $\alpha$-actinin on day 3 of differentiation. (B) Smad1/5/8 phosphorylation during the differentiation of the control cell line was assessed by immunoblotting. (C) Western blot analysis of three pooled samples for Matn2, Smad4 and p21 expression. Cytoskeletal $\beta$-actin served as a loading control. $t$, trimer; $d$, dimer; $m$, monomer. (D) QRT-PCR of three pooled parallel cultures using the SYBR green protocol.

the Nfia and Nfib species, whereas MyoD acted as a repressor (Fig. 6I,J). Coexpression of MyoD and Nfix did not relieve MyoD-mediated repression of the $\mathrm{P}_{\mathrm{d}}$, indicating that MyoD can fully block the activation by Nfix, in agreement with their competitive binding in EMSA assays and with MyoD highaffinity binding to a site overlapping Matn2 transcription 


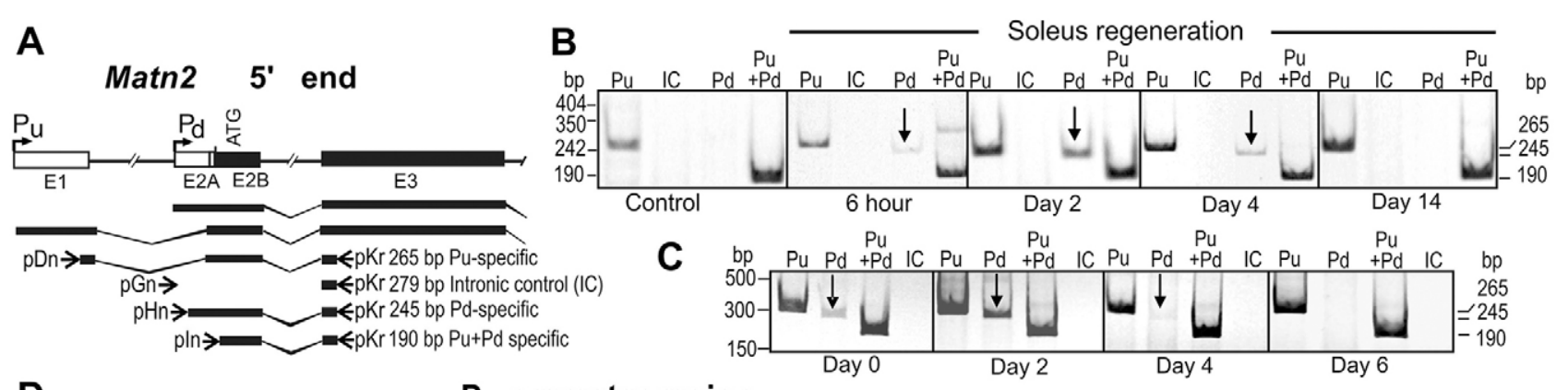

D

$P_{d}$ promoter region

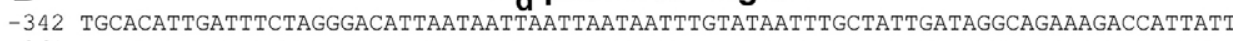
-261 ACCTGAATTCTAGGACCTCTTTTCCTTTTTTCACATCTAAGATGTAGAATGTGCCTATGATTAATAAATAGTACCTTGAA Nfi/MyoD
-181 GTCAAAAAAACCGTCAAGATAGATTTGTGATCCAAGGTGATGATAGACTTCCQATGGCCCTGCOAGCTCAAGAGAACTC
Myog -101 CG Myog $-21 \frac{\text { Myod } \quad+1}{\text { ATICAGGGCAATGGGGAGCAGCACCCTAACATCAGGGACACCCAGAAATCTAACTTGCCTTTCTCGTGTTGTATtATAGAGCT }}$

\section{Consensus sequences}

MYOD: GCANCTGNY

Nfi: TTGGCNNNNNGCCAA

Smad3: NNTNNTGTCTGGNNTNG

Smad: GTCTAGAC

Myog: GACAGCTGNN

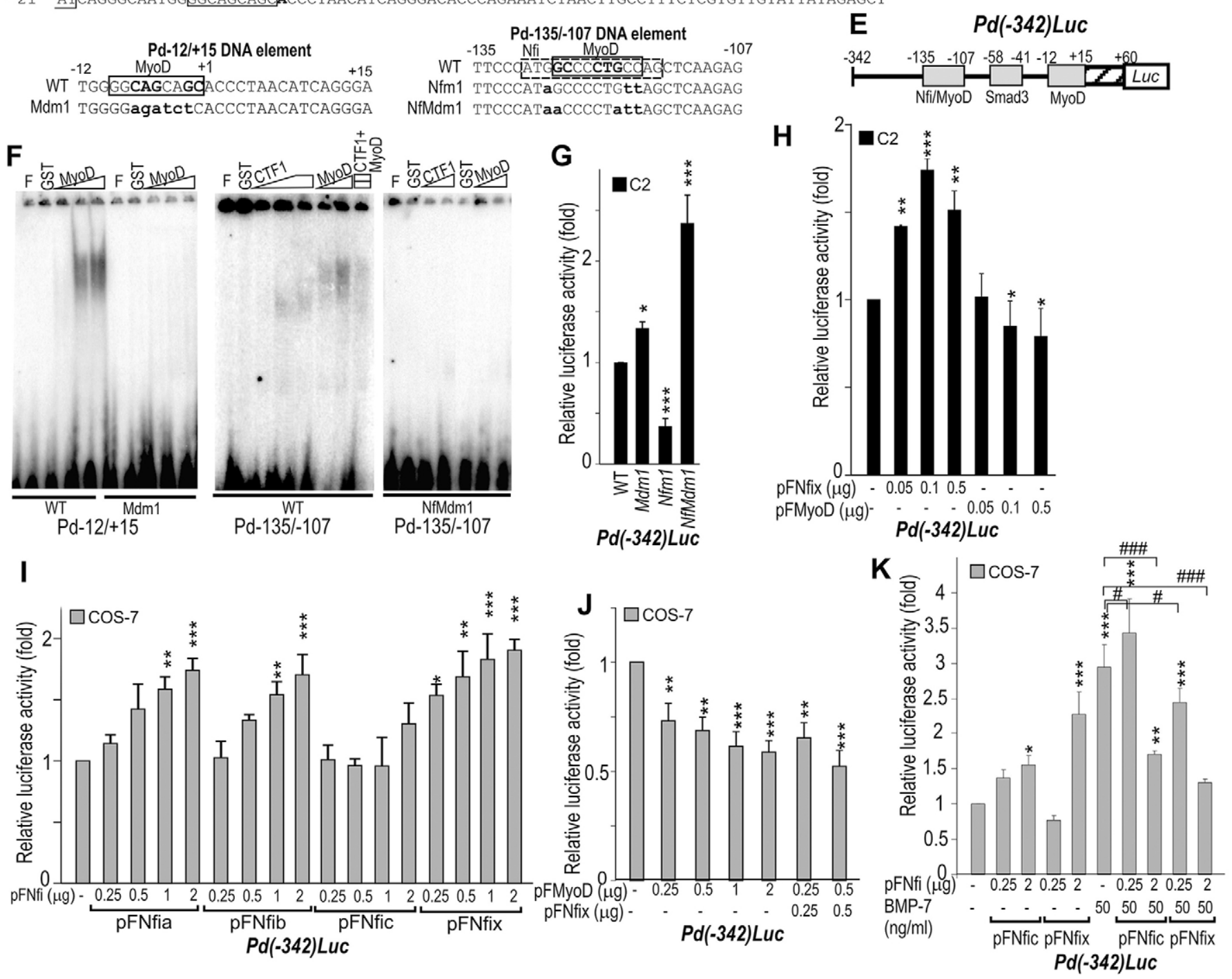

Fig. 6. See next page for legend.

initiation site. The Matn2 promoter also harbors putative Smad sites that might mediate the TGF- $\beta 1$ inhibitory effect (Fig. 6D). As BMP7 was reported to activate MATN2 and its promoter in other cells (Ichikawa et al., 2008), we also assessed the activation of the Matn2 promoter by BMP7. We found that BMP7 led to a threefold increase in $\mathrm{P}_{\mathrm{d}}$ activity and increased its transactivation by low doses of Nfic and Nfix (Fig. 6K).

Overall, we conclude that a transient increase in Matn $2 \mathrm{P}_{\mathrm{d}}$ activity results from the upregulation of NFI species in early myogenesis, whereas the expression of $\mathrm{MyoD}$ at later stages of 
Fig. 6. Regulation of the Matn2 promoter by MyoD and Nfi. (A) Schematic illustrating the exons E1-E3, the two alternative promoters and the Matn2 transcripts. Primer pairs specific for $\mathrm{P}_{\mathrm{u}}$ and $\mathrm{P}_{\mathrm{d}}$ and for intronic control (IC) are depicted (arrows), and have been described previously (Mátés et al., 2002). Semi-quantitative RT-PCR analysis using $\mathrm{P}_{\mathrm{u}}$ - and $\mathrm{P}_{\mathrm{d}}$-specific and control primer pairs during soleus regeneration (B) and C2 myoblast differentiation (C). (D) Nucleotide sequences showing the putative factor-binding sites in the $P_{d}$ region and in the wild-type (WT) and mutant versions of DNA elements $\mathrm{Pd}-12 /+15$ and $\mathrm{Pd}-135 /-107$. Mutated nucleotides are shown in lower case. (E) Structure of the $P_{d}$-luciferase fusion construct. $(F)$ The binding of purified GST (glutathione S-transferase), GST-MyoD and GST-CTF1 (NFIC isoform) to the wild-type and mutant $\mathrm{Pd}-12 /+15$ and $\mathrm{Pd}-135 /-107$ DNA elements was determined in EMSA. F, free probe. (G) The effect of the NFI and MyoD motif mutations shown in D on the $P_{d}$ activity of $P d(-342) L u c$ in C2 myoblasts. $(\mathrm{H}-\mathrm{K})$ The effect of forced expression of NFI proteins and MyoD from the indicated amounts of expression plasmids ( $\mathrm{pFNfi}$ and $\mathrm{pFMyoD}$ ) on the luciferase activity of $P d(-342) L u c$ in C2 myoblasts and COS-7 cells. In COS-7 cells, NFI proteins can increase $P_{d}$ activity $(\mathrm{I})$, whereas MyoD alone or upon coexpression with $\mathrm{Nfix}$ can repress it $(\mathrm{J})$. Bmp7 can increase $\mathrm{P}_{\mathrm{d}}$ activity and its dose-dependent activation by Nfic and Nfix $(\mathrm{K})$. Data represent the mean \pm s.e.m.; ${ }^{*} P<0.05,{ }^{* *} P<0.01$, ${ }^{* * *} P<0.001$ [relative to $P d(-342) L u c$ ], ${ }^{\#} P<0.05,{ }^{\# \#} P<0.001$ (as indicated).

differentiation might repress Matn2 expression. A mechanism involving Matn 2 activation at the onset of the myogenic program, together with the finding that Matn2 and Nfix each activate the expression of the other during early myoblast differentiation (Figs 4-6), explains the transient upregulation of Matn2 during myoblast differentiation and muscle regeneration. The initial increase in Matn2 expression at day 1 is expected to lead to an increase in Nfix and Nfia expression (Fig. 4I), which would further increase Matn2 expression. This positive-feedback regulatory loop would ensure high expression of Nfix, Nfia and Matn2 at early differentiation stages, whereas the later increase in MyoD expression would contribute to the downregulation of Matn2 expression in a negative-feedback loop during terminal myogenic differentiation.

\section{Matn2 deficiency impairs proper muscle regeneration in vivo} Similarly to rat muscles (Fig. 2A,G), high Matn2 signal was observed in nerves, tendons and MTJs, and the signal intensity in the epi-, peri- and endomysium was lower in adults than newborn mice (supplementary material Fig. S4A-G). To further establish the function of Matn2 in myogenesis in vivo, we next compared the regeneration of tibialis anterior muscle following notexin-induced injury in Matn 2 knockout (Matn2 $2^{-/-}$) and wild-type mice (Fig. 7). Significant differences were seen in the muscle weight to body weight ratio at days 3-5 (Fig. 7A). The average myofiber crosssectional area (CSA) did not differ significantly, but the myofiber size was more heterogeneous and fiber splitting occurred more frequently in Matn $2^{-1-}$ than in wild-type mice (Fig. 7B-D). The incidence of centrally nucleated myofibers increased fivefold in the untreated Matn $2^{-/-}$muscles, and the proportion of central myonuclei was also significantly higher in both the untreated and regenerating muscles of Matn2 $2^{-/-}$mice than in those of wildtype mice, indicating a mild muscular dystrophy (Fig. 7E,F; supplementary material Fig. S4H). Consistently, decreased desmin staining and an increased number of $\mathrm{Ki}^{+} 7^{+}$and $\mathrm{Ki}^{+} 7^{+} \mathrm{MyoD}^{+}$ cells were observed in Matn2-deficient mice at days 3 and 5 of regeneration, respectively (Fig. 7G,H). Immunofluorescence revealed a delayed regeneration in Matn2-deficient mice, as indicated by the delayed desmin staining and the large number of myoblasts still detected inside the basement membrane of the necrotized and regenerating Matn $2^{-/-}$muscle fibers at days 5 and
7 post-injury (Fig. 7I). At late stages of regeneration, signs of mild muscular dystrophy were seen in $\operatorname{Matn}^{-1-}$ mice, including necrosis, inflammation and increased fibrosis (Fig. 7I; Fig. 8A; supplementary material Fig. S4H). Central myonuclei and myofiber splitting also occurred more frequently, whereas fibrosis was not more pronounced in older Matn $2^{-1-}$ than in wild-type animals (supplementary material Fig. S4I,J).

Next, we tested the effect of Matn2 deficiency on the musclespecific gene expression in fetal limbs and myoblasts derived from newborn mice. Remarkably, QRT-PCR analysis revealed a 361-fold drop in Trf3 expression, followed by robust downregulation in the expression of Nfix, Nfia, Bmp 7 and late differentiation markers (Eno, Myhl) in Matn2 ${ }^{-1-}$ fetal limbs at embryonic day 16.5 (E16.5) (Table 1). Matn2 deficiency also significantly decreased the expression of the MyoD, Fak and Taf3 myogenesis regulators. Because an Nfix-directed switch from embryonic to fetal myogenesis takes place between E14.5 and E17.5 (Messina et al., 2010), along with the switch of the TFIID to a Trf3-Taf3-containing complex (Deato and Tjian, 2007), our data imply that Matn2 deficiency impairs the global switch towards terminal muscle differentiation by robustly preventing the induction of myogenic regulators, such as $\operatorname{Trf3}$ and Nfix.

The regulatory cascade induced by Matn2 is elicited by the myoblasts themselves, as the expression of $\operatorname{Trf} 3, \operatorname{Taf} 3, B m p 7$, MyoD, Fak, Nfic, Nfix and Itga 5 were all decreased in Matn2 ${ }^{-/-}$ versus Matn $2^{+/+}$cultured myoblasts (Table 1). When the kinetics of primary myoblast differentiation were assessed in differentiation medium, a transient 160-fold activation of Matn2 expression was accompanied by a $28-50$-fold transient induction of Tfr3, Taf3, Nfix, Nfic, Nfia and Bmp7 and by elevated expression of Itga and Fak in differentiating Matn $2^{+/+}$myoblasts (Fig. 8B). Interestingly, after a 50-100-fold activation on day 2, the levels of $M y o D$ and Myog peaked at day 7, following the earlier activation of $\mathrm{p} 21$ and $M y h 1$ with a kinetics similar to those of Trf3, Taf3 and Nfi.

By contrast, in the absence of Matn2, the expression of $\operatorname{Tr} 3$, Taf3, MyoD, Myog and other myogenic marker genes was not induced (Fig. 8B). Thus, Matn2 deficiency interfered with the transient activation of Nfix and Nfia regulating fetal and embryonic muscle genes, and it also prevented the induction of the Bmp7 and Nfic intermediates of the BMP/TGF- $\beta$ signaling pathways. Decreased Itga5 and Fak expression in Matn $2^{-/-}$myoblasts and during their differentiation, respectively, indicated that Matn2 deficiency can also affect integrin signaling (Fig. 8C,D). p42 (Erk2) phosphorylation was also inhibited in Matn $2^{-1-}$ mice (supplementary material Fig. S3C).

Taken together, our data indicate that the myoblast-secreted Matn2 is needed for $\operatorname{Tr} 3$ and Taf3 induction during differentiation, thereby selectively turning on the cascade of MRFs and Nfix, the activator of fetal muscle genes. Thus, we conclude that Matn2 acts as a key and early regulator of fetal myogenic differentiation, and that its transient activation and the feedback regulatory loops it forms with Nfix and MyoD might drive proper and timely BMP7 and integrin $\alpha 5$ signaling during the early stages of muscle differentiation.

\section{DISCUSSION}

Numerous studies of normal and myopathic muscles have underlined the crucial dependence of muscle development and function upon proper cell-ECM interactions. However, how this interaction can contribute to myogenic differentiation has remained poorly understood. This study uncovers a crucial role 

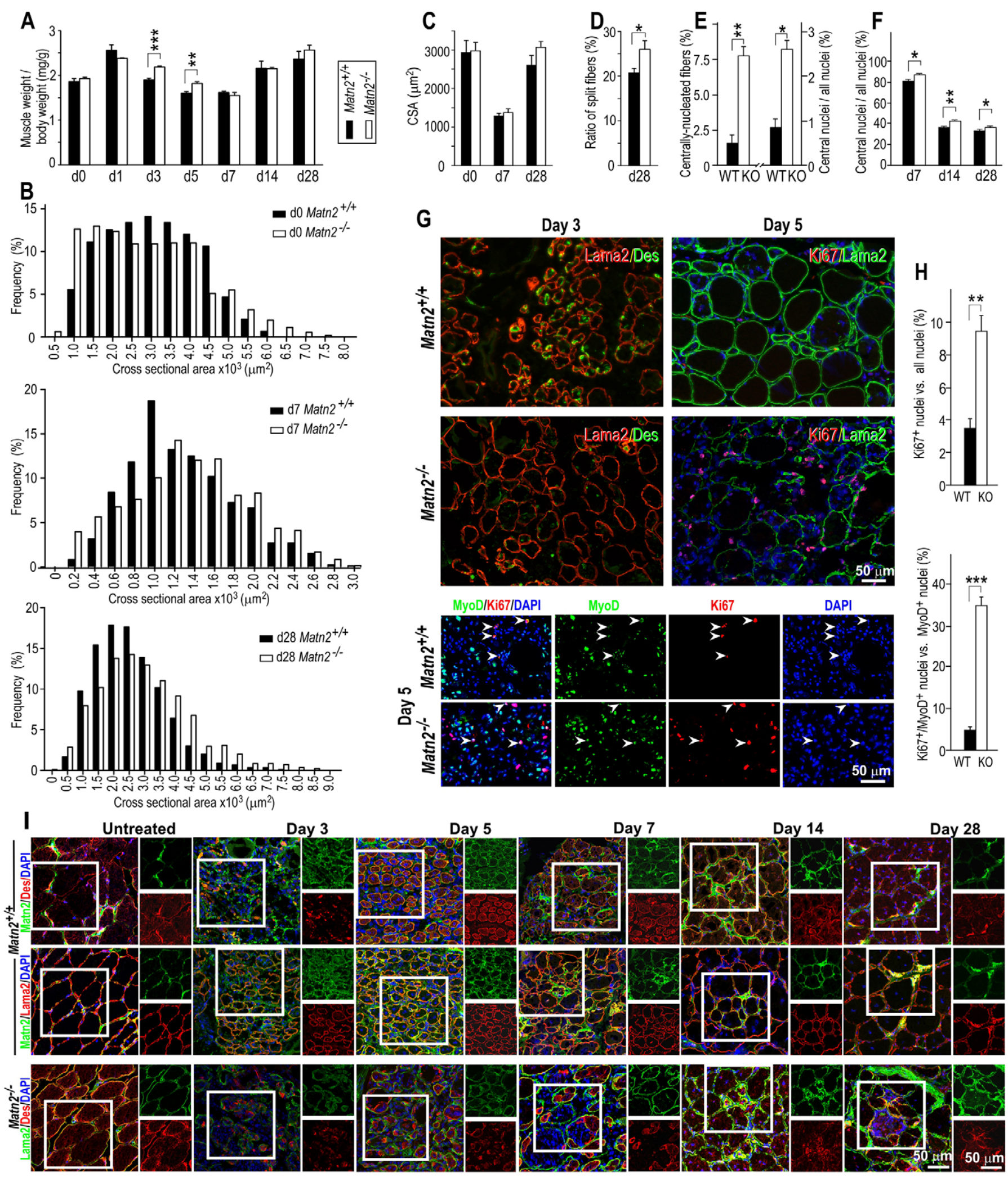

Day 14

Day 28

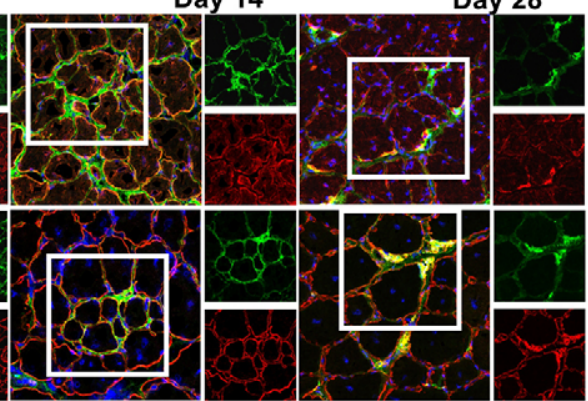

Fig. 7. See next page for legend

for the ECM component Matn2 in skeletal muscle differentiation and regeneration. We find that a transient upregulation of Matn2 followed by Matn2 deposition around proliferating, differentiating and fusing myoblasts is required for timely myoblast differentiation in culture and during muscle regeneration in vivo. This conclusion is supported by the finding that silencing or knockout of Matn2 delays myogenic differentiation from cultured myoblasts by inhibiting the activation of MRFs, p21, Nfix and other 
Fig. 7. Mild muscular dystrophy and delayed tibialis anterior muscle regeneration in Matn2 ${ }^{-1-}$ mice. (A-F) Tibialis anterior regeneration was quantified at the indicated days after notexin injection in wild-type (WT, closed bars) and Matn2 $2^{-1-}$ (KO, open bars) mice. (A) Weight changes during regeneration $(n=3-6)$. The CSA frequency distribution $(\mathrm{B})$ and average CSA (C) (300-400 myofibers/muscle, $n=3$ ). (D) Quantification of split myofibers on day 28 post-injury. The ratio of centrally nucleated versus all myofibers of untreated tibialis anterior ( $E$, left) and the ratio of non-peripheral versus all myonuclei of untreated ( $E$, right) and regenerating $(F)$ adult tibialis anterior are shown (2000 myonuclei/animal, $n=3)$. (G) Prolonged proliferation in Matn2-deficient regenerating muscles was revealed by Lama2/desmin, Ki67/ Lama2 and Ki67/MyoD immunofluorescence. Arrowheads point to Ki67 ${ }^{+}$MyoD $^{+}$cells. (H) Quantification of $\mathrm{Ki} 67^{+}$versus all nuclei and $\mathrm{Ki} 7^{+} \mathrm{MyoD}^{+}$nuclei within the $\mathrm{MyoD}^{+}$nuclei population $(10,000-30,000$ nuclei/animal group, $n=3$ ). (I) Double immunofluorescence indicates transient Matn2 upregulation between days 3-7 around desmin-positive myoblasts and myotubes. In Matn2-deficient mice, the numerous myoblasts still detected inside the basement membrane of regenerating myofibers on days 5 and 7 post-injury indicate delayed regeneration, whereas the enrichment of degenerating and regenerating myofibers on days 14 and 28 shows mild dystrophy. The outlined area is shown as single-channel images to the right of the main image. All quantitative data represent the mean \pm s.e.m.; ${ }^{*} P<0.05,{ }^{* *} P<0.01,{ }^{* * *} P<0.01$.

myogenesis-related genes. Conversely, rescuing Matn2 expression in Matn2-silenced myoblasts attenuated the delay in differentiation and restored the induction of Nfix and myogenic marker genes.

The muscle regeneration delay in $\operatorname{Matn}^{-/-}$mice was accompanied by a lack of $\operatorname{Trf} 3$ and Taf3 induction in vivo, thereby compromising the global transition of the core promoter complex and the activation of MRF (MyoD, Myog), p21 and muscle-specific genes $(M y h l)$. In addition to identifying Matn2 as an upstream global modulator of myogenic differentiation, these data further support the proposal that the Trf3-Taf3 complex plays a pivotal role in terminal muscle differentiation by specifically activating a subset of myogenic marker genes while inhibiting many others (Deato and Tjian, 2007; Deato et al., 2008; Jones, 2007). Matn2 deficiency also interferes with the activation of Nfix, which defines the fetal myogenic cell fate (Messina et al., 2010). This correlates well with the previous in vivo observation of Matn2 fetal-specific expression during the myoblast-myotube transition (Blais et al., 2005; Biressi et al., 2007; Mourikis et al., 2012). Matn2 might thus induce muscle-specific gene expression changes by coordinating various signaling pathways, as Matn2 deficiency also impairs the activation of genes involved in the Bmp7 and integrin $\alpha 5$ signaling pathways during differentiation.

Based on the present work and data available from the literature, we propose a hypothesis for the Matn2-dependent timely onset of myogenic differentiation (Fig. 8E). Our data show that Matn2 can modify integrin and other (e.g. Fak, Erk2) signaling pathways and that Matn2 deficiency dramatically impairs the activation of $\operatorname{Tr} 33$ expression and markedly delays the muscle differentiation program. Thus, the Matn2-elicited ECM signaling is needed to turn on $\operatorname{Tr} 3$, possibly by modifying the composition of multiprotein Smad complexes formed with other transcription factors. As the Trf3-Taf3 complex is known to activate $M y o D$ and to cause a global switch towards terminal differentiation (Deato and Tjian, 2007; Deato et al., 2008), this complex might mediate the Matn2-dependent upregulation of MRF and muscle-specific genes in myoblasts (Fig. 8E).

Whereas the loose ECM surrounding myoblasts favors growth factor signaling, the highly organized ECM of polynucleated myotubes and myofibers rather provides a reservoir, releasing growth factors upon damage (Fig. 8E). Matn2 might contribute to cell adhesion by its interaction with integrins and ECM proteins, such as collagens, fibrillins, laminin-nidogen complex and fibronectin (Piecha et al., 2002; Mann et al., 2007; Klatt et al., 2011). Working as an adaptor protein in the ECM, Matn2 might directly or indirectly modulate TGF- $\beta / \mathrm{BMP} / \mathrm{Smad}$ and other signaling pathways through its interaction with fibronectin and fibrillin. For instance, TGF- $\beta$ family members are stored in latent fibronectin- or fibrillin-bound structures in the ECM, and their activation requires integrin binding and contractile forces (Massagué, 2012). Matn2 deficiency also impaired p42 (Erk2) phosphorylation that was implicated in myoblast fusion (Knight and Kothary, 2011). However, further studies are required to fully understand how the extracellular Matn2-elicited signals are transduced to the cell nucleus.

Our model is in line with previous observations that TGF- $\beta 1$ acts to inhibit myoblast differentiation (Schabort et al., 2009). It also incorporates the finding that TGF- $\beta 1$ opposes BMP signaling and Matn 2 expression, thus preventing the onset of a positivefeedback loop whereby Matn2 and Nfix activate the expression of one another (Fig. 8E). This positive-feedback loop might ensure that sufficient levels of both Matn2 and Nfix are reached, such that Nfix can, in turn, promote the initiation of the musclespecific gene expression program driven by further positive autoregulatory loops formed by MyoD, Myog and p21 (Halevy et al., 1995; Walsh and Perlman, 1997; Aziz et al., 2010). This regulatory cascade fits well with prior observations of the concomitant induction of MRF genes (MyoD, Myog, Mef2a) and fetal muscle genes $(M y h 7)$ by forced $N f i x$ expression in embryonic myotubes and in differentiating C2 cells (Biressi et al., 2007; Messina et al., 2010).

By controlling the expression of regulatory and ECM target genes, Nfix can increase MyoD-dependent muscle-specific gene expression (Aziz et al., 2010). Whether Nfix can directly control the MyoD, Myog and/or p21 genes, and whether a feedback loop also occurs between these regulatory intermediates, remains to be established. However, this would be consistent with prior reports of Nfi-binding sites in the Myog and p21 promoters (Johanson et al., 1999; Ouellet et al., 2006), and with the finding that Nfi species can act as a cofactor in muscle-specific transcription (Funk and Wright, 1992; Messina et al., 2010). Our interpretation of a regulatory interplay between Nfix and cell cycle inhibitors, such as p21, is also supported by a previously described role of Nfix in the regulation of mitogenic pathways in other cell types (Nebl et al., 1994). Our conclusions are also in line with prior observations of regulatory relationships between TGF- $\beta$ and other Nfi species (Plasari et al., 2009; Plasari et al., 2010) and of BMP7 and Matn2 (Ichikawa et al., 2008) to control the timing of skin-wound healing. In keeping with these findings, we observed severe wound-healing defects in Matn $2^{-/-}$mice on a C57BL/6 genetic background (F. Deák and I. Kiss, data not shown). Our results provide evidence for a molecular mechanism whereby TGF- $\beta 1$-mediated regulation of Matn 2 might concomitantly control NFI expression.

Finally, our model provides a mechanistic explanation for the transient activation of Matn2, MyoD and Myog during myogenic differentiation. As $M y o D$ expression is turned on in response to increased expression of Matn2 and possibly also of Nfix, a negative-feedback loop can be established whereby MyoD, overcoming the effect of Nfix, will block Matn2 expression at late stages of differentiation (Fig. 8E). This is accompanied by the concomitant repression of Matn2, Nfix and MyoD, whereas the expression of MyoD targets and downstream regulators of myogenesis, such as Myog, persists until later stages, when 

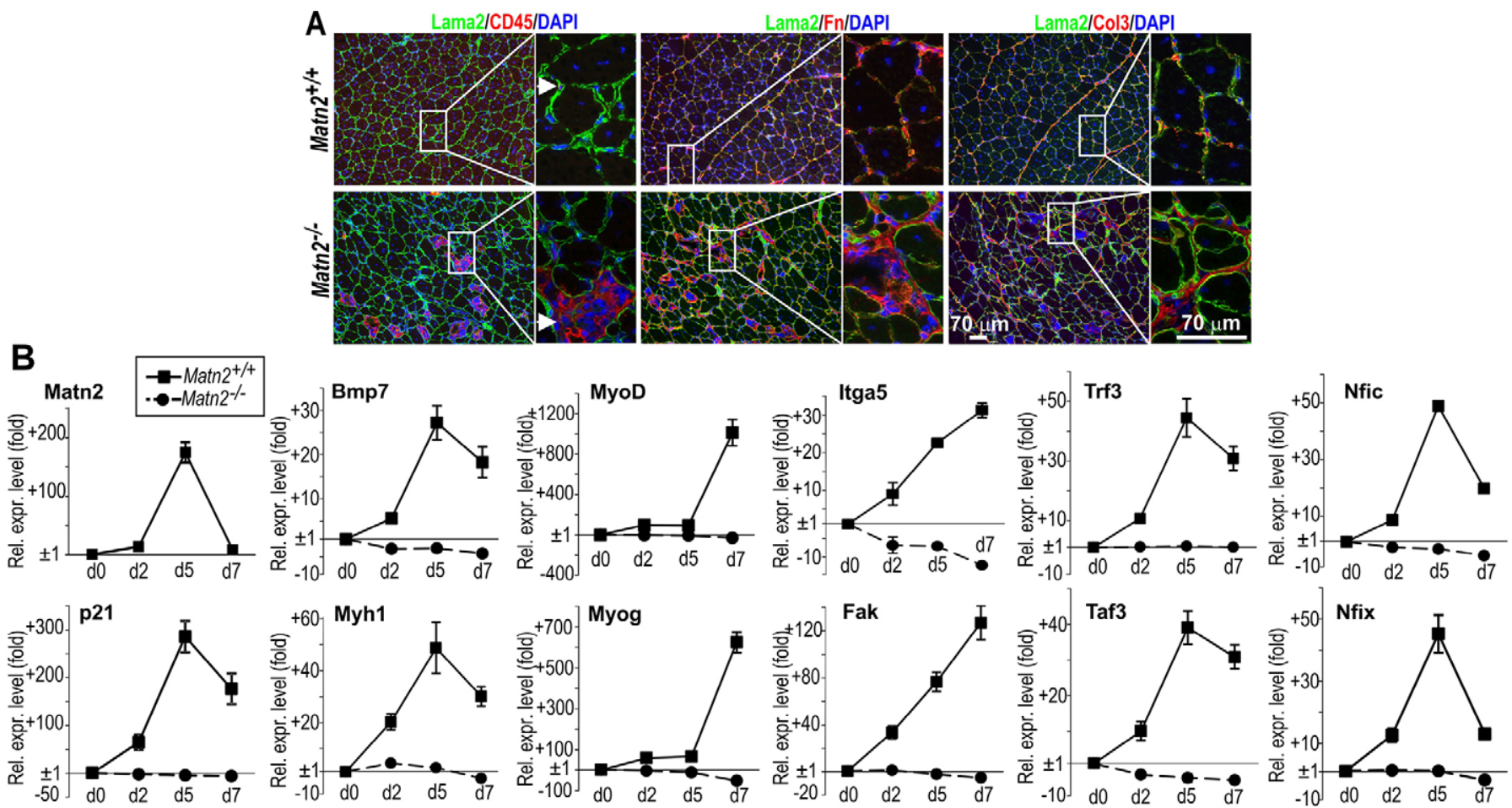

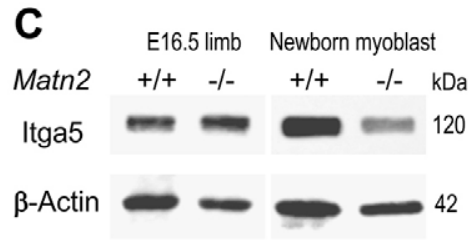

E

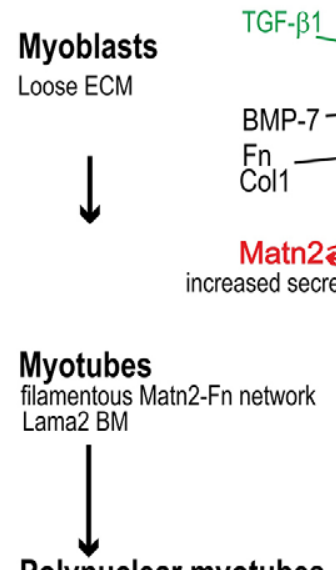

Polynuclear myotubes

Matn2 filaments connect other ECM components highly organized ECM - storage of growth factors complete BM

decreased Matn2 expression

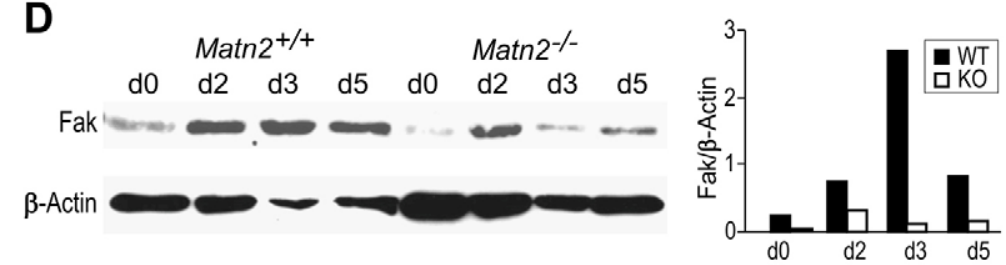

\section{Nucleus}


Table 1. Comparison of the expression levels of marker genes in fetal limbs and myoblast cultures from Matn2 $^{-/-}$versus wild-type mice by QRT-PCR

\begin{tabular}{|c|c|c|c|c|c|c|}
\hline \multirow[b]{2}{*}{ Gene symbol } & \multicolumn{3}{|l|}{ E16.5 fetal limbs } & \multicolumn{3}{|l|}{ Myoblast cultures } \\
\hline & Average ratio $^{a} \log 2(\Delta C \tau)$ & $P$ value & Fold change & Average ratio ${ }^{a} \log 2(\Delta C \tau)$ & $P$ value & Fold change \\
\hline Nfia & $-3.55 \pm 0.61$ & $7.2 \mathrm{E}-09^{\star * *}$ & -11.71 & $-0.55 \pm 0.07$ & $0.02^{*}$ & -1.46 \\
\hline Nfib & $-6.05 \pm 2.09$ & $3.73 \mathrm{E}-05^{\star * *}$ & -66.26 & $-0.40 \pm 0.37$ & 0.34 & -1.31 \\
\hline Nfic & $+0.01 \pm 0.34$ & 0.94 & +0.99 & $-0.97 \pm 0.24$ & $0.004^{* *}$ & -1.95 \\
\hline Nfix & $-1.35 \pm 0.68$ & $0.001^{* * *}$ & -2.55 & $-0.57 \pm 0.15$ & $0.02^{*}$ & -1.48 \\
\hline$M y o D$ & $-0.53 \pm 0.33$ & $0.006^{\star *}$ & -1.44 & $-1.39 \pm 0.21$ & $0.0004^{* * *}$ & -2.63 \\
\hline MyoG & $-1.59 \pm 0.29$ & $0.0006^{* * *}$ & -3.20 & $-1.42 \pm 018$ & $0.00001^{* * *}$ & -2.67 \\
\hline $\operatorname{ltga5}$ & $+0.24 \pm 0.34$ & 0.18 & +1.17 & $-0.90 \pm 0.30$ & $0.01^{* *}$ & -1.87 \\
\hline Bmp7 & $-1.87 \pm 0.46$ & $7.66 \mathrm{E}-07^{* * *}$ & -3.64 & $-1.84 \pm 0.71$ & $0.002^{\star *}$ & -3.59 \\
\hline Fak & $-0.93 \pm 0.69$ & $0.01^{* *}$ & -1.90 & $-1.27 \pm 0.42$ & $0.02^{*}$ & -2.42 \\
\hline Matn2 (ex1ex2) & no product in Matn $2^{-1-}$ embryos & & & no product in Matn $2^{-/-}$culture & & \\
\hline Trf3 & $-8.50 \pm 1.19$ & $3.87 \mathrm{E}-10^{* * *}$ & -360.79 & $-2.38 \pm 0.46$ & $0.0009^{* * *}$ & -5.21 \\
\hline Taf3 & $-0.64 \pm 0.56$ & $0.04^{*}$ & -1.56 & $-1.32 \pm 0.43$ & $0.03^{*}$ & -2.49 \\
\hline Myh1 & $-1.69 \pm 0.55$ & $0.03^{*}$ & -3.20 & $-0.69 \pm 0.25$ & $0.05^{\star}$ & -1.62 \\
\hline Eno & $-2.40 \pm 0.54$ & $0.0007^{* * *}$ & -5.27 & $-1.21 \pm 0.16$ & $0.002^{* *}$ & -2.31 \\
\hline Ckm & $+0.46 \pm 0.12$ & 0.4 & +1.37 & $-0.88 \pm 0.16$ & $0.006^{* *}$ & -1.84 \\
\hline p21 & $+0.43 \pm 0.33$ & 0.2 & +1.30 & $-0.82 \pm 0.13$ & $0.0014^{* *}$ & -1.76 \\
\hline
\end{tabular}

${ }^{\mathrm{a}}$ Mean \pm s.e.m., $\mathrm{n}=9 . \mathrm{C}_{\mathrm{t}}$ values were normalized to the $\mathrm{C}_{\mathrm{t}}$ value of the invariant $R p s 18$. ${ }^{*} P<0.05,{ }^{* *} P<0.01,{ }^{* * *} P<0.001$ (two-sample $t$-test).

components of terminally differentiated myofibers, such as Myh1, become expressed. The involvement of MRFs in Matn2 regulation is supported by recent online reports of chromatin immunoprecipitation data from the ENCODE consortium that reveal a possible binding of MyoD to the Matn2 promoter in C2 myoblasts and increased promoter occupancy by Myog in C2 myocytes.

In the absence of Matn2, BMP signaling alone or in combination with signaling by other ECM proteins might also activate MyoD and the myogenic regulatory program, but less efficiently and more slowly than upon $\operatorname{Tr} 33$ induction in the presence of Matn2 (Fig. 8E, black arrows). This can explain why Matn2 deficiency only delays myogenic differentiation, causing mild dystrophy, but does not block muscle differentiation or regeneration in transgenic mice, as $\mathrm{Matn}^{-/-}$mice develop without obvious abnormalities (Mátés et al., 2004). No deficiency in embryonic or fetal muscle development was observed by light microscopy. However, we recently observed that Matn $2^{-/-}$mice display an increased susceptibility to diethylnitrosamine-induced hepatocarcinogenesis (Fullár et al., 2014) and wound-healing defects with variable severity depending on the genetic background (F. Deák and I. Kiss, data not shown). Muscles of $\mathrm{Smad}^{-1-}$ mice also showed a mild myopathy, but denervation caused a dramatic atrophy (Sartori et al., 2013).

Overall, this work identifies Matn2 as an important ECM protein required for proper and timely myogenic differentiation and skeletal muscle regeneration. As TSCs induce and guide the sprouting of nerves at NMJs (Son et al., 1996), the Matn2-rich matrix produced by TSCs at NMJs possibly also facilitates the reinnervation process. Matn2 likely contributes to a broad range of repair processes, as it is expressed in a variety of committed proliferating cell types and it functions in regenerative processes of the liver (Szabó et al., 2007), skin (Ichikawa et al., 2008) and peripheral nerves (Malin et al., 2009). These data together support the hypothesis that Matn2 controls ECM-cell communication, and that it can thereby regulate the early steps of cell differentiation and repair processes of various tissues, in concert with NFI transcription factors and TGF- $\beta$ signaling pathways. Accordingly, other members of the NFI family have been implicated in other regenerative processes of adult tissue in the context of TGF- $\beta$ signaling. For instance, Nfic has been implicated in tooth morphogenesis, skin-wound healing and the onset of the follicle cycle leading to hair regeneration (Lee et al., 2009; Plasari et al., 2009; Plasari et al., 2010). An NFIC isoform was shown to harbor a TGF- $\beta$-responsive domain, and NFI-binding sites acting as TGF- $\beta$-responsive elements have been reported in several other ECM genes (Alevizopoulos et al., 1995; Alonso et al., 1996; Iozzo et al., 1997). Collectively, these findings link the NFI transcription factors and ECM target proteins, such as Matn2, to the regulation of the onset of a variety of adult tissue regeneration processes.

\section{MATERIALS AND METHODS \\ Animal treatment}

For this study, 3-month-old Wistar rats were anesthetized by intraperitoneal injection of $4 \%$ chloral hydrate $(10 \mu \mathrm{l} / \mathrm{g})$. Muscle necrosis was induced by intramuscular injection of $20 \mu \mathrm{g}$ of notexin, as described previously (Zádor et al., 1996). The animals were killed by an overdose of sodium pentobarbital. The entire soleus muscles of control or notexin-treated legs were removed, weighed and stored at $-80^{\circ} \mathrm{C}$ after freezing in isopentane cooled by liquid nitrogen.

The generation of Matn $2^{-/-}$mice has been reported previously (Mátés et al., 2004). Muscle regeneration was induced in 10-week-old Matn2 $2^{-/-}$ mice and wild-type littermates by injecting $0.3 \mu \mathrm{g}(60 \mu \mathrm{l})$ of notexin (Sigma-Aldrich) into the tibialis anterior muscle. All animal treatments were conducted in accordance with the National Institutes of Health Guide for the Care and Use of Laboratory Animals and under the approval of the Animal Health Care and Control Institute, Csongrád County, Hungary.

\section{Cell culture}

C2 myoblast cell line clone 7 (Yaffe and Saxel, 1977; Montarras et al., 1996) and primary myoblasts, which were prepared from the thigh muscle of neonatal mice as described previously (Springer et al., 1997), were propagated in growth medium containing $20 \%$ fetal bovine serum (FBS, Gibco) (Halevy et al., 1995). Differentiation was induced by switching the $80 \%$ confluent cultures to differentiation medium containing $2 \%$ horse serum, and this was defined as day 0 . The cultures were photographed with an Olympus Cell $\mathrm{R}$ microscope. In some experiments, $5 \mathrm{ng} / \mathrm{ml}$ TGF- $\beta 1$ (Immunotools) was added to differentiation medium on day 0 and was changed daily. Differentiation experiments were repeated at least three times. 


\section{Histology, immunohistochemistry and immunofluorescence}

The average CSA and fiber-size distributions were determined using the Digimizer software (MedCalc Software, Mariakerke, Belgium). Immunohistochemistry was performed as described previously (Piecha et al., 1999). Primary and secondary antibodies used for immunofluorescence of acetone-fixed $10-\mu \mathrm{m}$ cryosections and cells grown on coverslips are listed in supplementary material Table S1. Nonspecific binding of the antibodies was blocked with $10 \%$ proper normal serum. Nuclei were stained with DAPI. NMJs were detected with tetramethylrhodamine $\alpha$-bungarotoxin (Invitrogen, 1:200). The specimens were mounted with fluorescent mounting medium (Dako), viewed with a Nikon Eclipse E600 microscope equipped with epifluorescence and photographed with a Spot RT Slider camera. The images were processed using SPOT software (version 4.0.9 for Windows; Diagnostic Instruments). Figures were created with Adobe Photoshop 8.0 and CorelDraw X4 softwares.

\section{Protein extraction and immunoblot analysis}

The myoblast cell layer was extracted in ice-cold buffer containing $20 \mathrm{mM}$ Tris- $\mathrm{HCl} \mathrm{pH}$ 7.5, 0.15 M NaCl, 1 mM EDTA, 1 mM EGTA, 1\% Triton X-100 and protease inhibitors. After centrifugation at $10,000 \boldsymbol{g}$ for $10 \mathrm{~min}$ at $4^{\circ} \mathrm{C}$, supernatant proteins were separated by SDS-PAGE, blotted and developed as described previously (Piecha et al., 1999). Primary and HRP-conjugated secondary antisera are listed in supplementary material Table S1. Images were quantified with the Quantity One-4.2.3. program (BioRad). Experiments were repeated at least three times.

\section{RNA analysis}

Pooled total RNA was isolated from rat soleus muscles $(n=3)$ and used for northern analysis as described previously (Deák et al., 1997), using gene-specific cDNA fragments (supplementary material Table S2). For QRT-PCR, pooled total RNA was isolated from three cultures of differentiating $\mathrm{C} 2$ cell lines, three primary myoblast cultures grown either in growth medium or differentiating ex vivo in differentiation medium and also from E16.5 fetal limbs. QRT-PCR was performed with the SYBR green protocol, as described previously (Nagy et al., 2011). TaqMan probe sets and the TaqMan Gene Expression Master Mix (Applied Biosystems) were used with the following program: $15 \mathrm{~min}$ at $95^{\circ} \mathrm{C}$; 45 cycles of $95^{\circ} \mathrm{C}$ for $15 \mathrm{~s}$ and $60^{\circ} \mathrm{C}$ for $1 \mathrm{~min}$. Gene-specific primers and TaqMan probe sets are listed in supplementary material Table S2. Individual threshold cycle $\left(\mathrm{C}_{\mathrm{t}}\right)$ values were normalized either to the average $\mathrm{C}_{\mathrm{t}}$ values of three internal control genes (Hprt, Rps 18 and CycloAb) (SYBR green) or to the $\mathrm{C}_{\mathrm{t}}$ values of Hprt (TaqMan probe). Relative gene expression levels are presented as $\log _{2}$ ratios or fold values.

\section{Silencing and rescuing Matn2 expression}

We designed shRNA targeting Matn2 using the program RNAi explorer (Fig. 4D). Oligonucleotides were annealed, phosphorylated and inserted into the $\mathrm{pFP} / \mathrm{Neo}-\mathrm{H} 1$ vector (Kaufman et al., 2005), following recommendations for the pSUPER system to generate the derivative KD2639. A total of $1 \times 10^{5} \mathrm{C} 2$ myoblasts were co-transfected in growth medium with $500 \mathrm{ng}$ of purified KD2639 or pFP/Neo-H1 control DNA and $50 \mathrm{ng}$ of pFvFP helper vector using ExGene 500 (Fermentas). At $24 \mathrm{~h}$ after plating, the cells were seeded into 10 -cm dishes for a 2-week selection in growth medium containing $500 \mu \mathrm{g} / \mathrm{ml} \mathrm{G} 418$ (Cambrex), and stably transfected Matn2-silenced cell lines were established from G418resistant single colonies.

To rescue Matn2 silencing, we modified the cDNA encoding fulllength mouse Matn2 by mutating the sequence targeted by the shRNA but preserving its protein coding capacity (Fig. 4D). The modified cDNA was inserted into the pCEP-Pu expression vector and the recombinant plasmid was introduced into the sh3 cell line silenced for Matn2. Clones that were resistant to $1 \mu \mathrm{g} / \mathrm{ml}$ puromycin were pooled. Independent control (Ctrl), silenced (sh3, sh4, and sh7) cell lines and rescued (sh3res2) cultures were tested for myogenic differentiation and marker gene expression in at least three independent experiments.

\section{Cell proliferation and differentiation assays}

The MTS assay for mitochondrial function was performed with the CellTiter96 AQueous One solution cell proliferation kit (Promega), according to the manufacturer's protocol. For the evaluation of differentiation, myoblast cultures were stained for sarcomeric $\alpha$ actinin and nuclei (DAPI). In randomly chosen microscope fields containing a total of 3000-4000 nuclei, $\alpha$-actinin-positive myoblasts were counted. Primary myotube frequency was calculated as the number of myotubes containing $<3$ nuclei divided by the total number of cells in a given microscope field. The fusion index was defined as the number of myotubes harboring $\geq 3$ nuclei divided by the total number of cells. The differentiation index was defined as the number of myotube nuclei divided by the total number of nuclei. Data represent the mean \pm s.e.m. from three to five independent experiments.

\section{Alternative promoter analysis}

$1-\mu 1$ aliquots of total RNA samples treated with RNase-free DNase (Roche Molecular Biochemicals) were subjected to oligo(dT)primed first-strand cDNA synthesis, followed by PCR using promoterspecific primer pairs (Fig. 6A), as described previously (Mátés et al., 2002).

\section{EMSA}

The program Jaspar was used to search for putative NFI and MyoD recognition sequences in the Matn2 promoter and to synthesize doublestranded oligonucleotides (Fig. 6D). Constructs encoding GST-CTF1, an isoform of the human NFIC (Alevizopoulos et al., 1995) and GST-MyoD (Biesiada et al., 1999) were expressed, and the proteins were purified essentially as described previously (Nagy et al., 2011). 20-30 fmol of end-labeled wild-type and mutant DNA probes were incubated with 0.6$2.5 \mu \mathrm{g}$ of GST or GST-MyoD in the presence of $300 \mathrm{ng}$ of poly(dIdC)•poly(dI-dC), as described previously (Biesiada et al., 1999). To test NFI binding, the probes were incubated with $1.25-2.5 \mu \mathrm{g}$ of GST-CTF1 or with $1.25 \mu \mathrm{g}$ each of GST-fused CTF1 and MyoD, as described previously (Szabó et al., 1995), and separated by electrophoresis on a prerun $5 \%$ polyacrylamide gel.

\section{Transient expression assay}

$P d(-342) L u c$ was constructed by inserting the $-342 /+60 \mathrm{P}_{\mathrm{d}}$ fragment into the PvuII/PstI site of the pGL3-Basic Vector (Promega). Derivatives carrying point mutations in the MyoD motif near the start site (Mdm1, $\mathrm{Pd}-12 /+15)$ in the NFI motif $(\mathrm{Nfm} 1)$ or in both the NFI and MyoD consensus sequences (NfMdm1) of the Nfi/MyoD composite element Pd-135/-107 were made using the PCR based QuikChange ${ }^{\mathrm{TM}}$ SiteDirected Mutagenesis kit (Stratagene).

C2 myoblasts (cultured in growth medium) and COS-7 cells were transfected with 3-5 $\mu \mathrm{g}$ of wild-type and mutant reporters in six-well plates using ExGene 500 (Fermentas) or the calcium phosphate coprecipitation method, respectively, and luciferase activities were measured, as described previously (Nagy et al., 2011). Forced expression assays were performed with $3-5 \mu \mathrm{g}$ of reporters and increasing amounts of expression plasmids for MyoD (pFMyoD, a gift from Vittorio Sartorelli) or mouse NFI proteins (pFNfia, pFNfib, $\mathrm{pFNfic}$ and $\mathrm{pFNfix}$ ). The latter plasmids harbour the coding sequences of mouse NFI genes (Chaudhry et al., 1998) in pcDNA5'UT-FLAG, as described previously (Nagy et al., 2011). The effect of $50 \mathrm{ng} / \mathrm{ml} \mathrm{BMP7}$ (ImmunoTools) was tested in Opti-MEM ${ }^{\circledR}$ (Gibco). Transfection mixtures were adjusted with the appropriate empty vectors to the same amount of total DNA. Luciferase activities were expressed as fold values relative to that for $P d(-342) L u c$. Results are the mean \pm s.e.m. from at least three independent experiments.

\section{Statistical analysis}

Data are presented as the mean \pm s.e.m. Statistical significance was determined using a one-way analysis of variance (ANOVA) with KyPlot version 2.0 beta $15 ; * P<0.05$, ** $P<0.01$, *** $P<0.001$. 


\section{Acknowledgements}

We thank Zoltán Ivics (Max Delbrück Center for Molecular Medicine, Berlin, Germany) for the gift of pFP/Neo-H1 vector, Raimund Wagener (University of Cologne, Cologne, Germany) for Matn2 antiserum and Vittorio Sartorelli, (University of Southern California, Los Angeles, CA) for the MyoD expression plasmids. We also thank Anikó Simon, Erzsébet Balásházy, Klaudia Kávai, Emőke Horváth, Katalin Hegedüs and Gabriella Lehőcz for excellent technical assistance, Anikó Görbe and Ernő Zádor for technical advice and Mária Tóth for the artwork

\section{Competing interests}

The authors declare no competing interests.

\section{Author contributions}

F.D., L.M., É.K., Á.Z., T.S., M.K., L.Me., A.K., B.Ó. and H.J. performed experiments and analyzed data; L.S. and L.D. contributed reagents and evaluated results; N.M. provided materials, interpreted data and edited the manuscript; L.M. and L.G.P. designed and evaluated experiments and financed revisions; I.K. conceived the research and wrote the manuscript.

\section{Funding}

This work was supported by grants from the Hungarian Scientific Research Fund (OTKA) [grant number TO49608]; and the Medical Research Council, Hungary (ETT) [grant number 008/2006] to I.K.; and by grants from OTKA [grant number PD-101421]; and Marie Curie [grant number FP7-PEOPLE-2011-CIG 304077] to L.M. Funding was also supplied by the European Union, co-financed by the European Regional Fund [grant numbers GOP-1.3.1-11/B-2011-0002 to Avidin Ltd., TÁMOP-4.2.2-1-2008-0013 and TÁMOP-4.2.2.A-11-1-KONV-2012-0035]. Á.Z. and L.Me. were supported by the János Bolyai fellowship of the Hungarian Academy of Sciences [grant numbers BO_00781/11/8 and BO/00349/03, respectively]. Deposited in PMC for immediate release.

\section{Supplementary material}

Supplementary material available online at

http://jcs.biologists.org/lookup/suppl/doi:10.1242/jcs.141556/-/DC1

\section{References}

Alevizopoulos, A., Dusserre, Y., Tsai-Pflugfelder, M., von der Weid, T., Wahli, W. and Mermod, N. (1995). A proline-rich TGF-beta-responsive transcriptional activator interacts with histone H3. Genes Dev. 9, 3051-3066.

Alonso, C. R., Pesce, C. G. and Kornblihtt, A. R. (1996). The CCAAT-binding proteins CP1 and NF-I cooperate with ATF-2 in the transcription of the fibronectin gene. J. Biol. Chem. 271, 22271-22279.

Aziz, A., Liu, Q. C. and Dilworth, F. J. (2010). Regulating a master regulator: establishing tissue-specific gene expression in skeletal muscle. Epigenetics $\mathbf{5}$, 691-695.

Biesiada, E., Hamamori, Y., Kedes, L. and Sartorelli, V. (1999). Myogenic basic helix-loop-helix proteins and Sp1 interact as components of a multiprotein transcriptional complex required for activity of the human cardiac alpha-actin promoter. Mol. Cell. Biol. 19, 2577-2584.

Biressi, S., Tagliafico, E., Lamorte, G., Monteverde, S., Tenedini, E., Roncaglia, E., Ferrari, S., Ferrari, S., Cusella-De Angelis, M. G., Tajbakhsh, S. et al. (2007) Intrinsic phenotypic diversity of embryonic and fetal myoblasts is revealed by genome-wide gene expression analysis on purified cells. Dev. Biol. 304, 633-651.

Blais, A., Tsikitis, M., Acosta-Alvear, D., Sharan, R., Kluger, Y. and Dynlacht, B. D. (2005). An initial blueprint for myogenic differentiation. Genes Dev. 19, 553-569.

Chargé, S. B. and Rudnicki, M. A. (2004). Cellular and molecular regulation of muscle regeneration. Physiol. Rev. 84, 209-238.

Chaudhry, A. Z., Vitullo, A. D. and Gronostajski, R. M. (1998). Nuclear factor I (NFI) isoforms differentially activate simple versus complex NFI-responsive promoters. J. Biol. Chem. 273, 18538-18546.

Deák, F., Piecha, D., Bachrati, C., Paulsson, M. and Kiss, I. (1997). Primary structure and expression of matrilin-2, the closest relative of cartilage matrix protein within the von Willebrand factor type A-like module superfamily. J. Biol. Chem. 272, 9268-9274.

Deák, F., Wagener, R., Kiss, I. and Paulsson, M. (1999). The matrilins: a novel family of oligomeric extracellular matrix proteins. Matrix Biol. 18, 55-64.

Deato, M. D. and Tjian, R. (2007). Switching of the core transcription machinery during myogenesis. Genes Dev. 21, 2137-2149.

Deato, M. D., Marr, M. T., Sottero, T., Inouye, C., Hu, P. and Tjian, R. (2008). MyoD targets TAF3/TRF3 to activate myogenin transcription. Mol. Cell 32, 96105.

Fullár, A., Baghy, K., Deák, F., Péterfia, B., Zsák, Y., Tátrai, P., Schaff, Z., Dudás, J., Kiss, I. and Kovalszky, I. (2014). Lack of Matrilin-2 favors liver tumor development via Erk1/2 and GSK-3 $\beta$ pathways in vivo. PLoS ONE 9, e93469.

Funk, W. D. and Wright, W. E. (1992). Cyclic amplification and selection of targets for multicomponent complexes: myogenin interacts with factors recognizing binding sites for basic helix-loop-helix, nuclear factor 1, myocyte-specific enhancer-binding factor 2, and COMP1 factor. Proc. Natl. Acad. Sci. USA 89, 9484-9488.

Gardner, S., Alzhanov, D., Knollman, P., Kuninger, D. and Rotwein, P. (2011). TGF- $\beta$ inhibits muscle differentiation by blocking autocrine signaling pathways initiated by IGF-II. Mol. Endocrinol. 25, 128-137.

Goetsch, S. C., Hawke, T. J., Gallardo, T. D., Richardson, J. A. and Garry, D. J. (2003). Transcriptional profiling and regulation of the extracellular matrix during muscle regeneration. Physiol. Genomics 14, 261-271.

Goody, M. F. and Henry, C. A. (2010). Dynamic interactions between cells and their extracellular matrix mediate embryonic development. Mol. Reprod. Dev. 77, 475-488.

Gorbe, A., Becker, D. L., Dux, L., Stelkovics, E., Krenacs, L., Bagdi, E. and Krenacs, T. (2005). Transient upregulation of connexin43 gap junctions and synchronized cell cycle control precede myoblast fusion in regenerating skeletal muscle in vivo. Histochem. Cell Biol. 123, 573-583.

Gronostajski, R. M. (2000). Roles of the NFI/CTF gene family in transcription and development. Gene 249, 31-45.

Grubb, B. D., Harris, J. B. and Schofield, I. S. (1991). Neuromuscular transmission at newly formed neuromuscular junctions in the regenerating soleus muscle of the rat. J. Physiol. 441, 405-421.

Gullberg, D., Velling, T., Lohikangas, L. and Tiger, C. F. (1998). Integrins during muscle development and in muscular dystrophies. Front. Biosci. 3, D1039-D1050.

Halevy, O., Novitch, B. G., Spicer, D. B., Skapek, S. X., Rhee, J., Hannon, G. J., Beach, D. and Lassar, A. B. (1995). Correlation of terminal cell cycle arrest of skeletal muscle with induction of p21 by MyoD. Science 267, 1018-1021.

Ichikawa, T., Suenaga, Y., Koda, T., Ozaki, T. and Nakagawara, A. (2008). DeltaNp63/BMP-7-dependent expression of matrilin-2 is involved in keratinocyte migration in response to wounding. Biochem. Biophys. Res. Commun. 369, 994-1000.

Iozzo, R. V., Pillarisetti, J., Sharma, B., Murdoch, A. D., Danielson, K. G., Uitto, J. and Mauviel, A. (1997). Structural and functional characterization of the human perlecan gene promoter. Transcriptional activation by transforming growth factorbeta via a nuclear factor 1-binding element. J. Biol. Chem. 272, 5219-5228.

Johanson, M., Meents, H., Ragge, K., Buchberger, A., Arnold, H. H. and Sandmöller, A. (1999). Transcriptional activation of the myogenin gene by MEF2-mediated recruitment of myf5 is inhibited by adenovirus E1A protein. Biochem. Biophys. Res. Commun. 265, 222-232.

Jones, K. A. (2007). Transcription strategies in terminally differentiated cells: shaken to the core. Genes Dev. 21, 2113-2117.

Kaufman, C. D., Izsvák, Z., Katzer, A. and Ivics, Z. (2005). Frog Prince transposon-based RNAi vectors mediate efficient gene knockdown in human cells. J. RNAi Gene Silencing 1, 97-104.

Klatt, A. R., Becker, A. K., Neacsu, C. D., Paulsson, M. and Wagener, R. (2011). The matrilins: modulators of extracellular matrix assembly. Int. J. Biochem. Cell Biol. 43, 320-330

Knight, J. D. and Kothary, R. (2011). The myogenic kinome: protein kinases critical to mammalian skeletal myogenesis. Skelet. Muscle. 1, 29.

Lee, D. S., Park, J. T., Kim, H. M., Ko, J. S., Son, H. H., Gronostajski, R. M., Cho, M. I., Choung, P. H. and Park, J. C. (2009). Nuclear factor I-C is essential for odontogenic cell proliferation and odontoblast differentiation during tooth root development. J. Biol. Chem. 284, 17293-17303.

Malin, D., Sonnenberg-Riethmacher, E., Guseva, D., Wagener, R., Aszódi, A., Irintchev, A. and Riethmacher, D. (2009). The extracellular-matrix protein matrilin 2 participates in peripheral nerve regeneration. J. Cell Sci. 122, 995-1004.

Mann, H. H., Sengle, G., Gebauer, J. M., Eble, J. A., Paulsson, M. and Wagener, R. (2007). Matrilins mediate weak cell attachment without promoting focal adhesion formation. Matrix Biol. 26, 167-174.

Massagué, J. (2012). TGF $\beta$ signalling in context. Nat. Rev. Mol. Cell Biol. 13, 616630.

Mátés, L., Korpos, E., Déak, F., Liu, Z., Beier, D. R., Aszódi, A. and Kiss, I. (2002). Comparative analysis of the mouse and human genes (Matn2 and MATN2) for matrilin-2, a filament-forming protein widely distributed in extracellular matrices. Matrix Biol. 21, 163-174.

Mátés, L., Nicolae, C., Mörgelin, M., Deák, F., Kiss, I. and Aszódi, A. (2004). Mice lacking the extracellular matrix adaptor protein matrilin-2 display normal embryonic and adult development. Matrix Biol. 23, 195-204.

Messina, G., Biressi, S., Monteverde, S., Magli, A., Cassano, M., Perani, L., Roncaglia, E., Tagliafico, E., Starnes, L., Campbell, C. E. et al. (2010). Nfix regulates fetal-specific transcription in developing skeletal muscle. Cell 140, 554-566.

Montarras, D., Aurade, F., Johnson, T., Ilan, J., Gros, F. and Pinset, C. (1996). Autonomous differentiation in the mouse myogenic cell line, $\mathrm{C} 2$, involves a mutual positive control between insulin-like growth factor II and MyoD, operating as early as at the myoblast stage. J. Cell Sci. 109, 551-560.

Mourikis, P., Gopalakrishnan, S., Sambasivan, R. and Tajbakhsh, S. (2012). Cell-autonomous Notch activity maintains the temporal specification potential of skeletal muscle stem cells. Development 139, 4536-4548.

Nagy, A., Kénesi, E., Rentsendorj, O., Molnár, A., Szénási, T., Sinkó, I., Zvara, A., Oommen, S. T., Barta, E., Puskás, L. G. et al. (2011). Evolutionarily conserved, growth plate zone-specific regulation of the matrilin-1 promoter: LSox5/Sox6 and Nfi factors bound near TATA finely tune activation by Sox9. Mol. Cell. Biol. 31, 686-699.

Nebl, G., Mermod, N. and Cato, A. C. (1994). Post-transcriptional downregulation of expression of transcription factor NF1 by Ha-ras oncogene. J. Biol. Chem. 269, 7371-7378. 
Osses, N. and Brandan, E. (2002). ECM is required for skeletal muscle differentiation independently of muscle regulatory factor expression. Am. J. Physiol. 282, C383C394.

Ouellet, S., Vigneault, F., Lessard, M., Leclerc, S., Drouin, R. and Guérin, S. L. (2006). Transcriptional regulation of the cyclin-dependent kinase inhibitor $1 \mathrm{~A}$ (p21) gene by NFI in proliferating human cells. Nucleic Acids Res. 34, 64726487.

Piecha, D., Muratoglu, S., Mörgelin, M., Hauser, N., Studer, D., Kiss, I., Paulsson, M. and Deák, F. (1999). Matrilin-2, a large, oligomeric matrix protein, is expressed by a great variety of cells and forms fibrillar networks. J. Biol. Chem. 274, 13353-13361.

Piecha, D., Wiberg, C., Mörgelin, M., Reinhardt, D. P., Deák, F., Maurer, P. and Paulsson, M. (2002). Matrilin-2 interacts with itself and with other extracellular matrix proteins. Biochem. J. 367, 715-721.

Plasari, G., Calabrese, A., Dusserre, Y., Gronostajski, R. M., McNair, A., Michalik, L. and Mermod, N. (2009). Nuclear factor I-C links platelet-derived growth factor and transforming growth factor beta1 signaling to skin wound healing progression. Mol. Cell. Biol. 29, 6006-6017.

Plasari, G., Edelmann, S., Högger, F., Dusserre, Y., Mermod, N. and Calabrese, A. (2010). Nuclear factor I-C regulates TGF-beta-dependent hair follicle cycling. J. Biol. Chem. 285, 34115-34125.

Ringelmann, B., Roder, C., Hallmann, R., Maley, M., Davies, M., Grounds, M. and Sorokin, L. (1999). Expression of laminin alpha1, alpha2, alpha4, and alpha5 chains, fibronectin, and tenascin- $C$ in skeletal muscle of dystrophic 129ReJ dy/dy mice. Exp. Cell Res. 246, 165-182.

Sanes, J. R. (2003). The basement membrane/basal lamina of skeletal muscle. J. Biol. Chem. 278, 12601-12604

Sartori, R., Milan, G., Patron, M., Mammucari, C., Blaauw, B., Abraham, R. and Sandri, M. (2009). Smad2 and 3 transcription factors control muscle mass in adulthood. Am. J. Physiol. 296, C1248-C1257.

Sartori, R., Schirwis, E., Blaauw, B., Bortolanza, S., Zhao, J., Enzo, E., Stantzou, A., Mouisel, E., Toniolo, L., Ferry, A. et al. (2013). BMP signaling controls muscle mass. Nat. Genet. 45, 1309-1318.

Schabort, E. J., van der Merwe, M., Loos, B., Moore, F. P. and Niesler, C. U. (2009). TGF-beta's delay skeletal muscle progenitor cell differentiation in an isoform-independent manner. Exp. Cell Res. 315, 373-384.

Schuler, F. and Sorokin, L. M. (1995). Expression of laminin isoforms in mouse myogenic cells in vitro and in vivo. J. Cell Sci. 108, 3795-3805.

Sesodia, S. and Cullen, M. J. (1991). The effect of denervation on the morphology of regenerating rat soleus muscles. Acta Neuropathol. 82, 21-32.
Shi, X. and Garry, D. J. (2006). Muscle stem cells in development, regeneration, and disease. Genes Dev. 20, 1692-1708.

Son, Y. J., Trachtenberg, J. T. and Thompson, W. J. (1996). Schwann cells induce and guide sprouting and reinnervation of neuromuscular junctions. Trends Neurosci. 19, 280-285.

Springer, M. L., Rando, T. and Blau, H. M. (1997, revised 2002). Gene delivery to muscle. In Current Protocols in Human Genetics (ed. A. L. Boyle), Unit 13.4. New York, NY: John Wiley \& Sons.

Szabó, P., Moitra, J., Rencendorj, A., Rákhely, G., Rauch, T. and Kiss, I. (1995). Identification of a nuclear factor-I family protein-binding site in the silencer region of the cartilage matrix protein gene. J. Biol. Chem. 270, 10212-10221.

Szabó, E., Lódi, C., Korpos, E., Batmunkh, E., Rottenberger, Z., Deák, F., Kiss, I., Tokés, A. M., Lotz, G., László, V. et al. (2007). Expression of matrilin-2 in oval cells during rat liver regeneration. Matrix Biol. 26, 554-560.

Thorsteinsdóttir, S., Deries, M., Cachaço, A. S. and Bajanca, F. (2011). The extracellular matrix dimension of skeletal muscle development. Dev. Biol. 354, 191-207.

Wagers, A. J. and Conboy, I. M. (2005). Cellular and molecular signatures of muscle regeneration: current concepts and controversies in adult myogenesis. Cell 122, 659-667.

Walsh, K. and Perlman, H. (1997). Cell cycle exit upon myogenic differentiation. Curr. Opin. Genet. Dev. 7, 597-602.

Winbanks, C. E., Weeks, K. L., Thomson, R. E., Sepulveda, P. V., Beyer, C., Qian, H., Chen, J. L., Allen, J. M., Lancaster, G. I., Febbraio, M. A. et al. (2012). Follistatin-mediated skeletal muscle hypertrophy is regulated by Smad3 and mTOR independently of myostatin. J. Cell Biol. 197, 997-1008.

Winbanks, C. E., Chen, J. L., Qian, H., Liu, Y., Bernardo, B. C., Beyer, C., Watt, K. I., Thomson, R. E., Connor, T., Turner, B. J. et al. (2013). The bone morphogenetic protein axis is a positive regulator of skeletal muscle mass. J. Cell Biol. 203, 345-357.

Yaffe, D. and Saxel, O. (1977). Serial passaging and differentiation of myogenic cells isolated from dystrophic mouse muscle. Nature 270, 725-727.

Yin, H., Price, F. and Rudnicki, M. A. (2013). Satellite cells and the muscle stem cell niche. Physiol. Rev. 93, 23-67.

Yokoyama, S. and Asahara, H. (2011). The myogenic transcriptional network. Cell. Mol. Life Sci. 68, 1843-1849.

Zádor, E., Mendler, L., Ver Heyen, M., Dux, L. and Wuytack, F. (1996). Changes in mRNA levels of the sarcoplasmic/endoplasmic-reticulum $\mathrm{Ca}(2+)$-ATPase isoforms in the rat soleus muscle regenerating from notexin-induced necrosis. Biochem. J. 320, 107-113. 
A

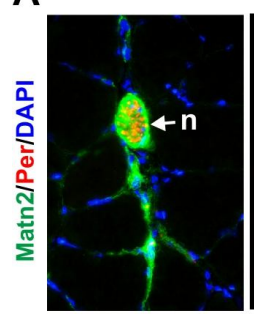

C

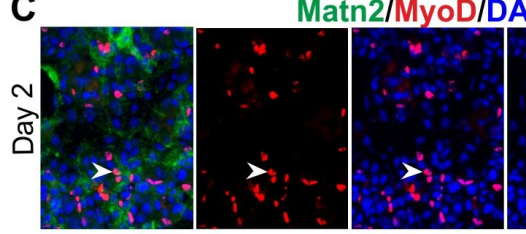

Untreated
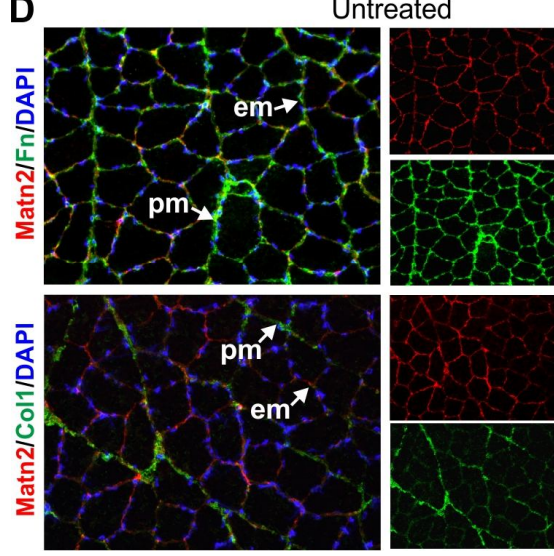

Untreated

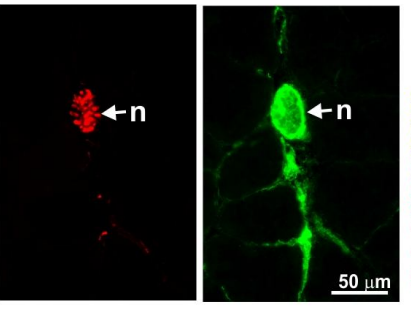

API
B

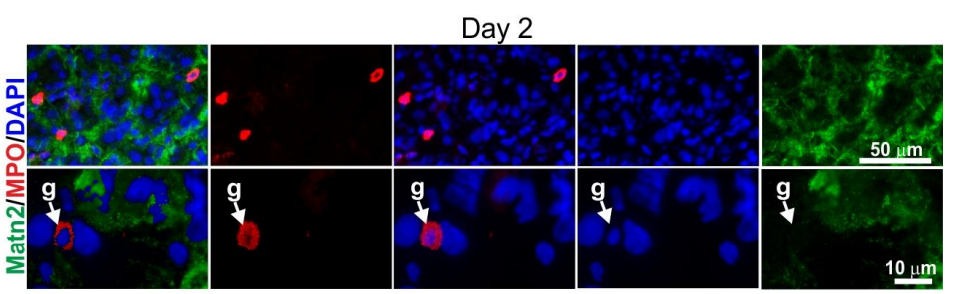

Matn2/Myog/DAPI

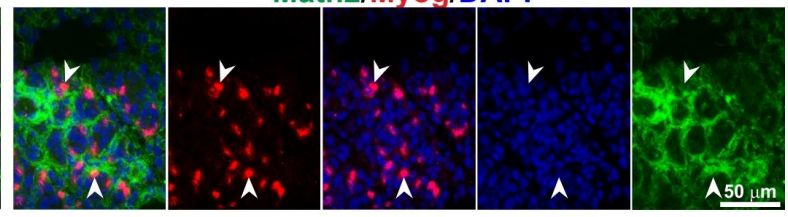

Day 7
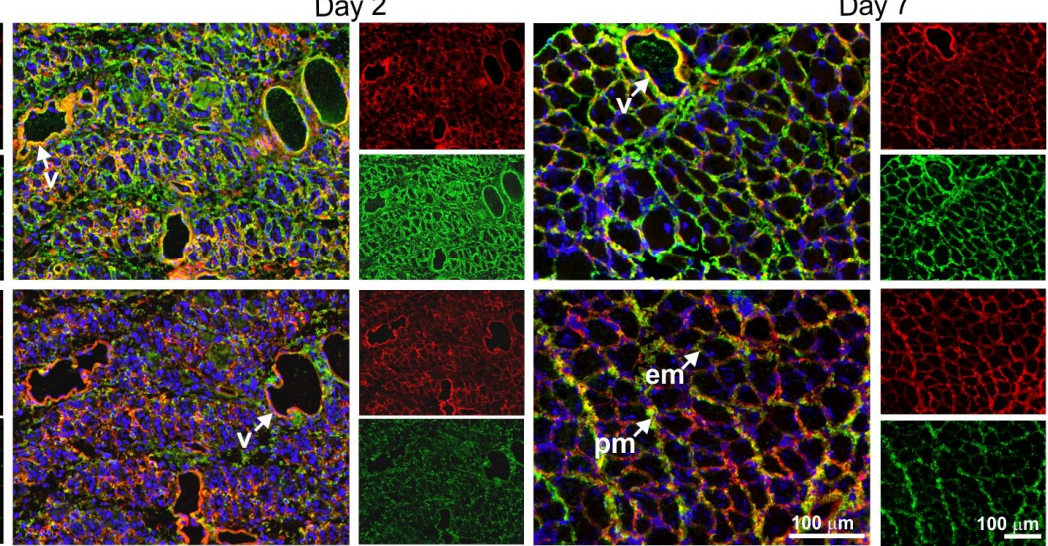

Fig. S1. Double immunofluorescence staining for Matn2 and other markers during rat soleus regeneration. (A) Strong Matn2 staining around nerve fibers visualized by peripherin (Per) staining in the untreated soleus. (B) Lack of Matn2 staining around granulocytes (g) expressing myeloperoxidase (MPO) two days postinjury. (C) Deposition of Matn2 around MyoD- and Myog-expressing cells (arrowhead) on day 2 of regeneration. (D) Matn2 shows partial colocalization with fibronectin (Fn) and collagen-1 (Col1) in the endomysium and perimysium of untreated and regenerating muscles. The colocalization of Matn2 and fibronectin is most evident on day 2 after treatment and around blood vessels. All three ECM proteins exhibit broader expression domain on days 2 and 7 of muscle regeneration compared to that of the untreated control muscle. Other symbols are as in Fig. 2. 
A
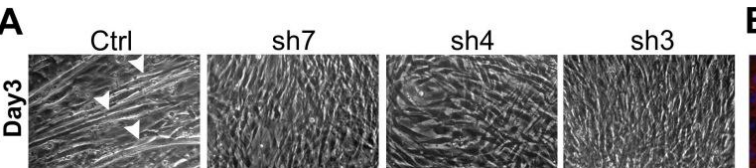

B Ctrl
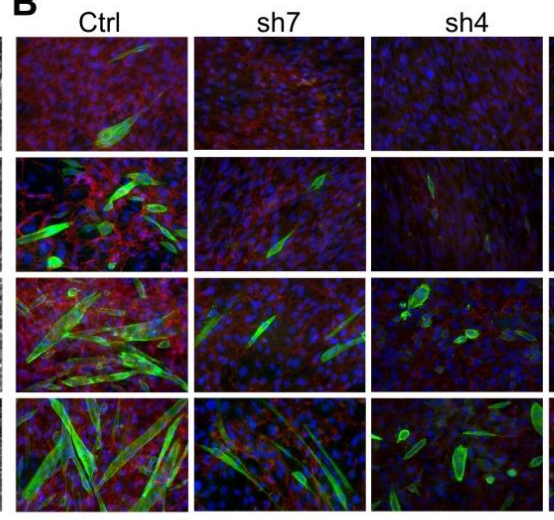

sh3
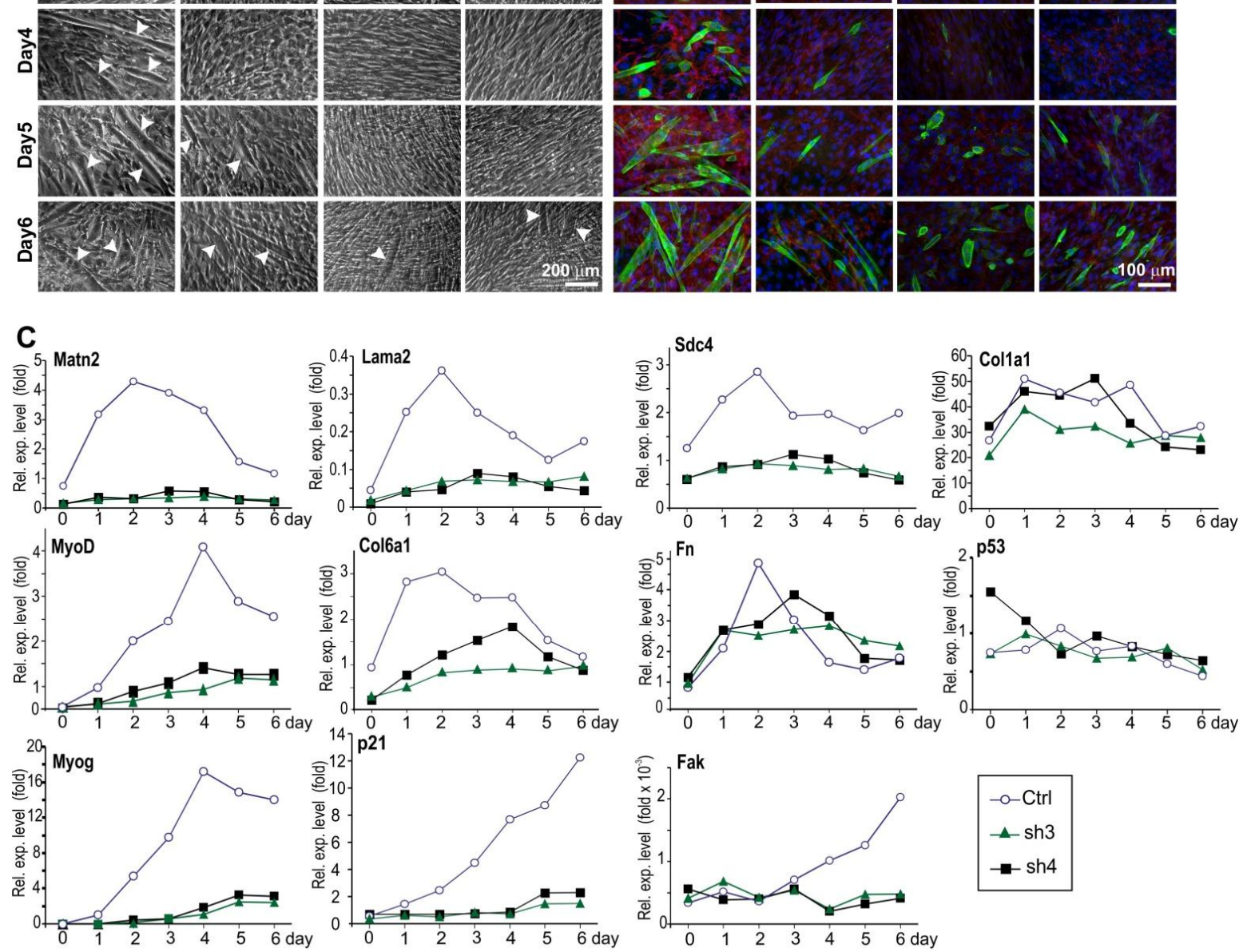

Fig. S2. Delayed myogenic differentiation and marker gene expression in various Matn2-silenced C2 cell lines. Comparison of phase-contrast microscopy (A), immunofluorescence (B) and marker mRNA levels $(\mathbf{C})$ of parallel cultures of the $\mathrm{Ctrl}$ and silenced myoblast cell lines upon differentiation in DM. (A) Arrowheads point at multinucleated myotubes. (B) Double immunofluorescence staining of the cultures for Matn2 (red) and sarcomeric $\alpha$-actinin (green). Note that the $\alpha$-actinin-positive myotubes appear later, they are narrower and mononuclear in the Matn2-silenced cultures. (C) Marker gene expression measured by QRT-PCR analysis using the SYBR green protocol is plotted in fold relative to three internal control genes to illustrate reproducibility. 
A
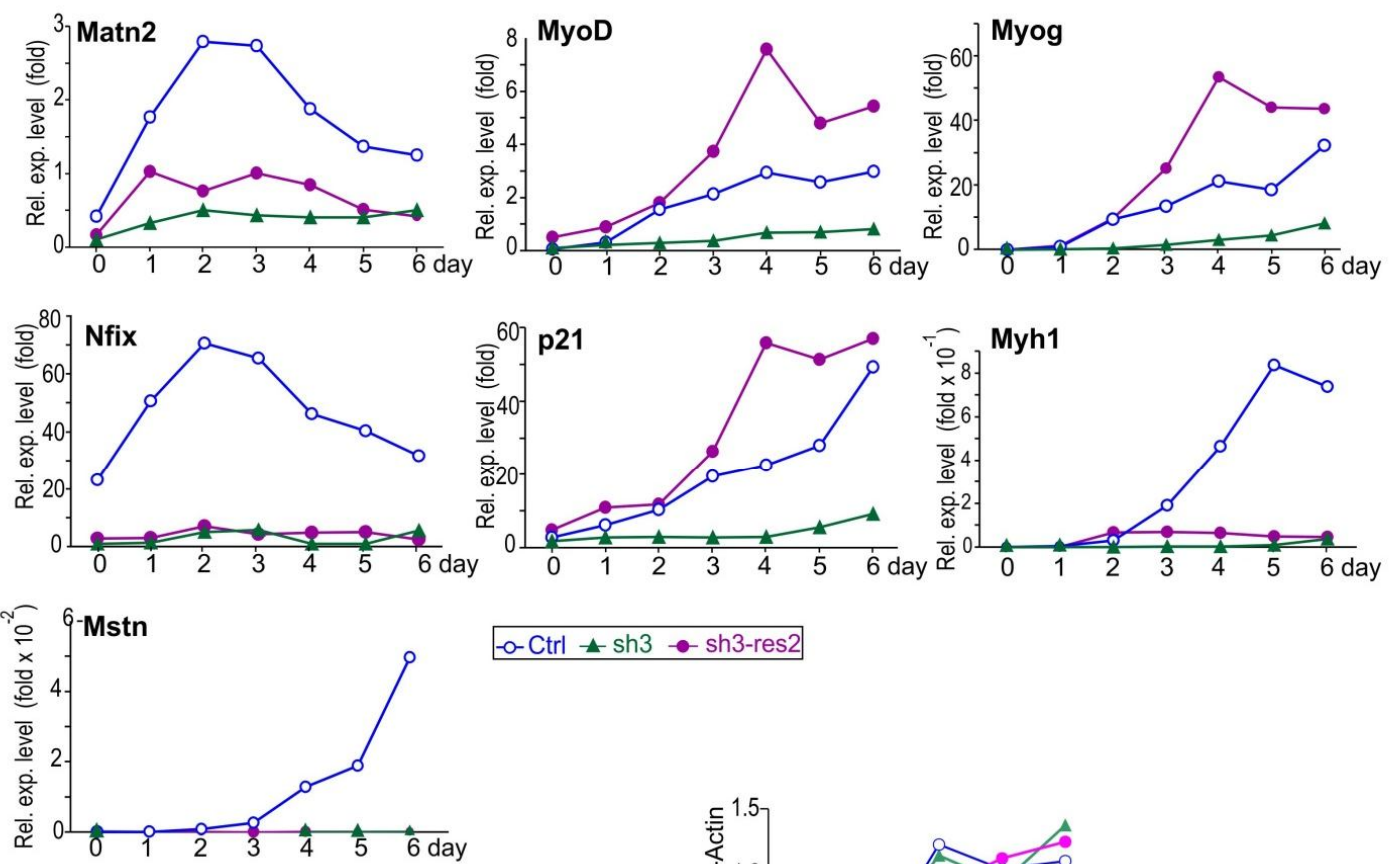

B

sh3

Ctrl sh3-res2

$-\mathrm{o}-\mathrm{Ctrl} \_$sh $3 \bullet$ sh3-res 2

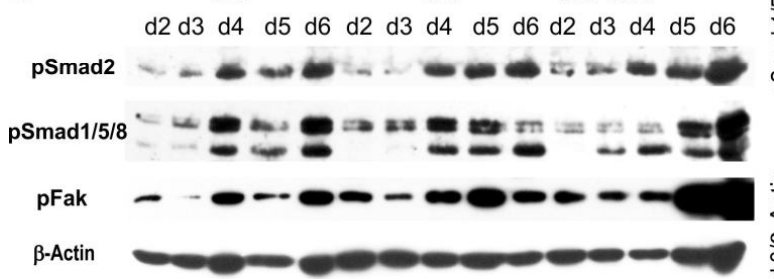

C
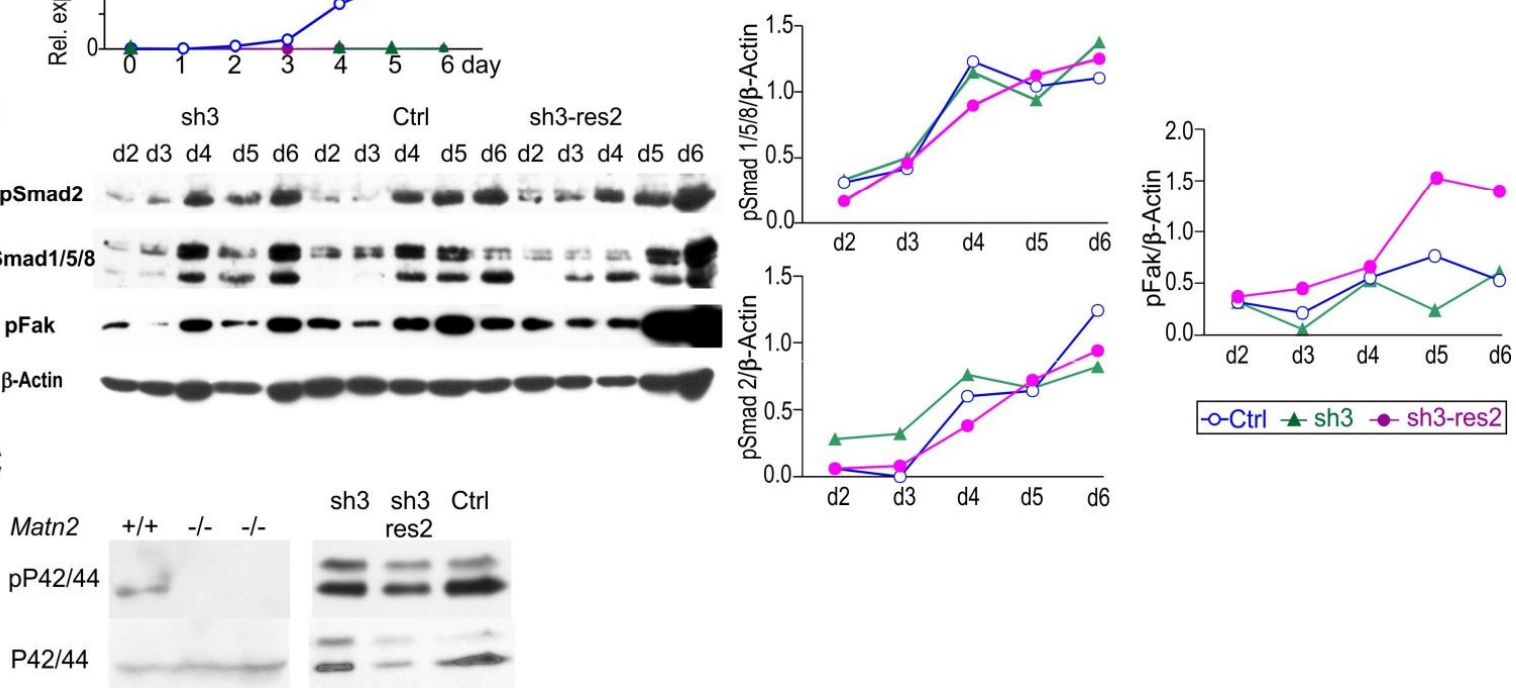

Fig. S3. Marker gene expression changes in differentiating Matn2-silenced and rescued myoblasts cultures. (A) Expression of Nfix and the early and late myogenic marker genes depends on the rescued Matn2 level. QRT-PCR analysis performed with TaqMan probes from another differentiation experiment of control, silenced and rescued myoblasts in DM is shown for comparison with Fig. 4I. Marker mRNA levels are presented as fold values relative to that of the HPRT mRNA. (B) Level of pSmads and pFAK in the sh3, Ctrl and rescued sh3-res2 myoblast cultures and quantification of the results. (C) Absence of Matn 2 affects P42/P44 phosphorylation in muscles of newborn mice (left panel) and in C2 myoblast cultures on day 2 of differentiation (right panel). 

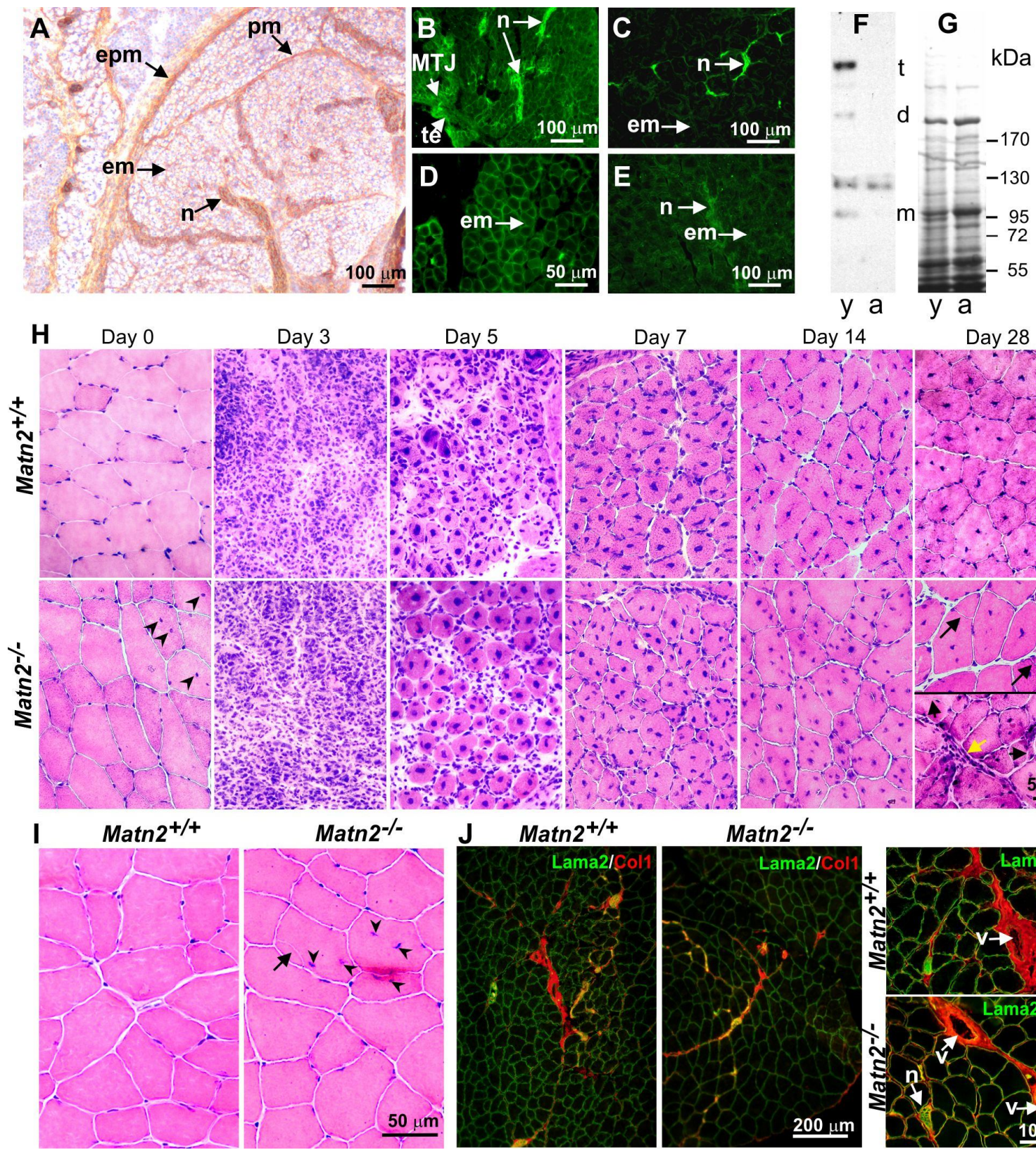

Day 5

Day 7

Day 14

Day 28
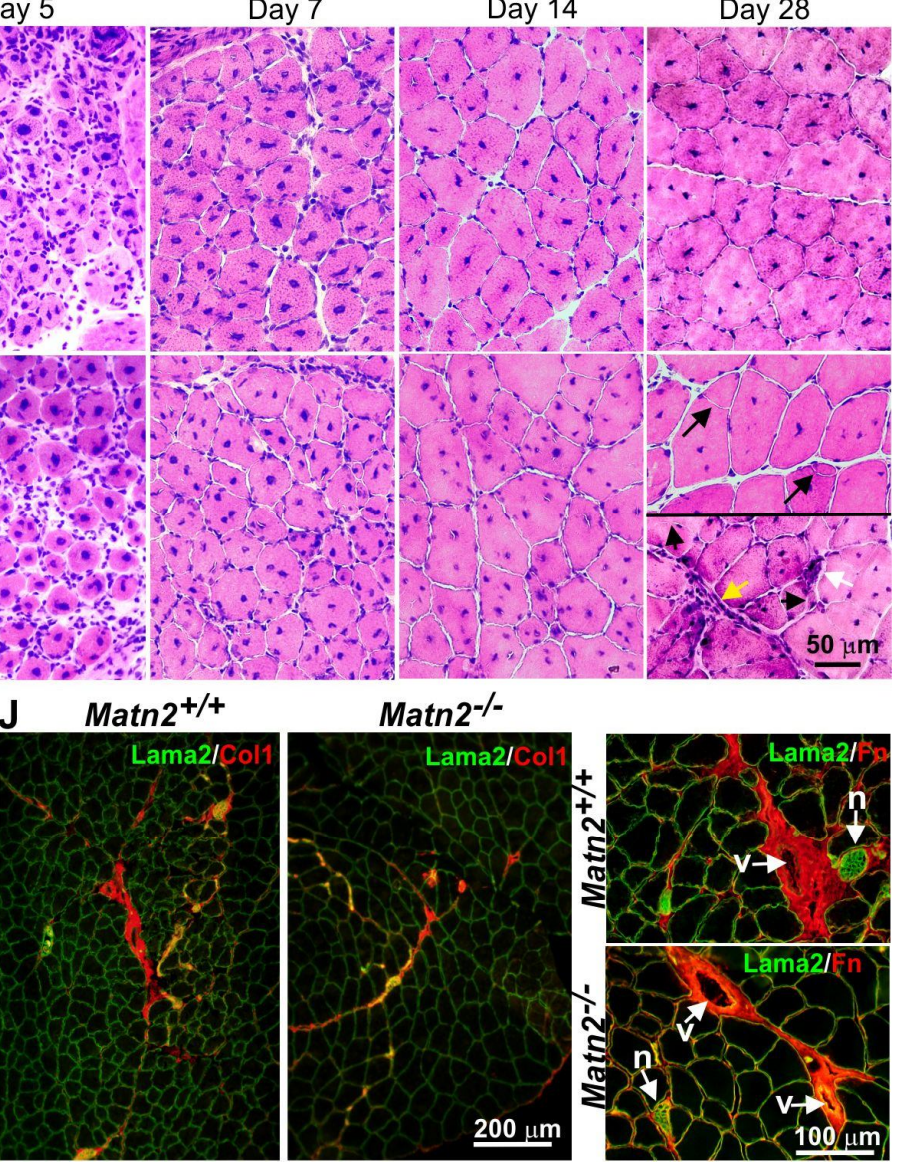

Fig. S4. Matn2 distribution in mouse skeletal muscle and notexin-induced TA regeneration. Matn2 immunohistochemistry (A) and immunofluorescence (B-E) in transverse cryosections of forelimb (A-C) and skull (D-E) muscles of newborn (A,B,D) and adult (C,E) mice. Deposition is seen in the epimysium (epm), perimysium, endomysium, nerves, MTJ and tendon (te). The signal intensities are moderate in the endomysium of muscle fibers in newborn animals and decreased further in adults. Immunoblot detection of Matn2 (F) and Coomassie Brilliant Blue staining (G) of muscle extracts of 15-day-old (y) and adult (a) mouse thigh. Without sample reduction, Matn2 is resolved predominantly as a trimer, but dimer, monomer and proteolytically processed forms are also visible in young mice (F). (H,I) H\&E staining of TA cross sections from WT and Matn2 $2^{-/}$mice during regeneration $(\mathrm{H})$ and at the age of 10 months (I). Arrowheads denote non-peripheral nuclei in untreated $\mathrm{Matn}^{-/-}$mice, black arrows point to split fibers. In addition to fiber splitting, necrotic fibers with invading cells (white arrow) and increased ECM deposition (yellow 
arrow) also occur in some areas of Matn2-deficient muscles on day 28 of regeneration $(\mathrm{H})$. (J) Double staining of 10-month-old mouse TA shows collagen-1 and fibronectin deposition in connective tissues, especially around nerves and blood vessels, without signs of increased fibrosis in Matn $2^{-/}$mice. Other symbols are as in Figs. 1-3. 
Table S1. Primary and secondary antibodies used in the study

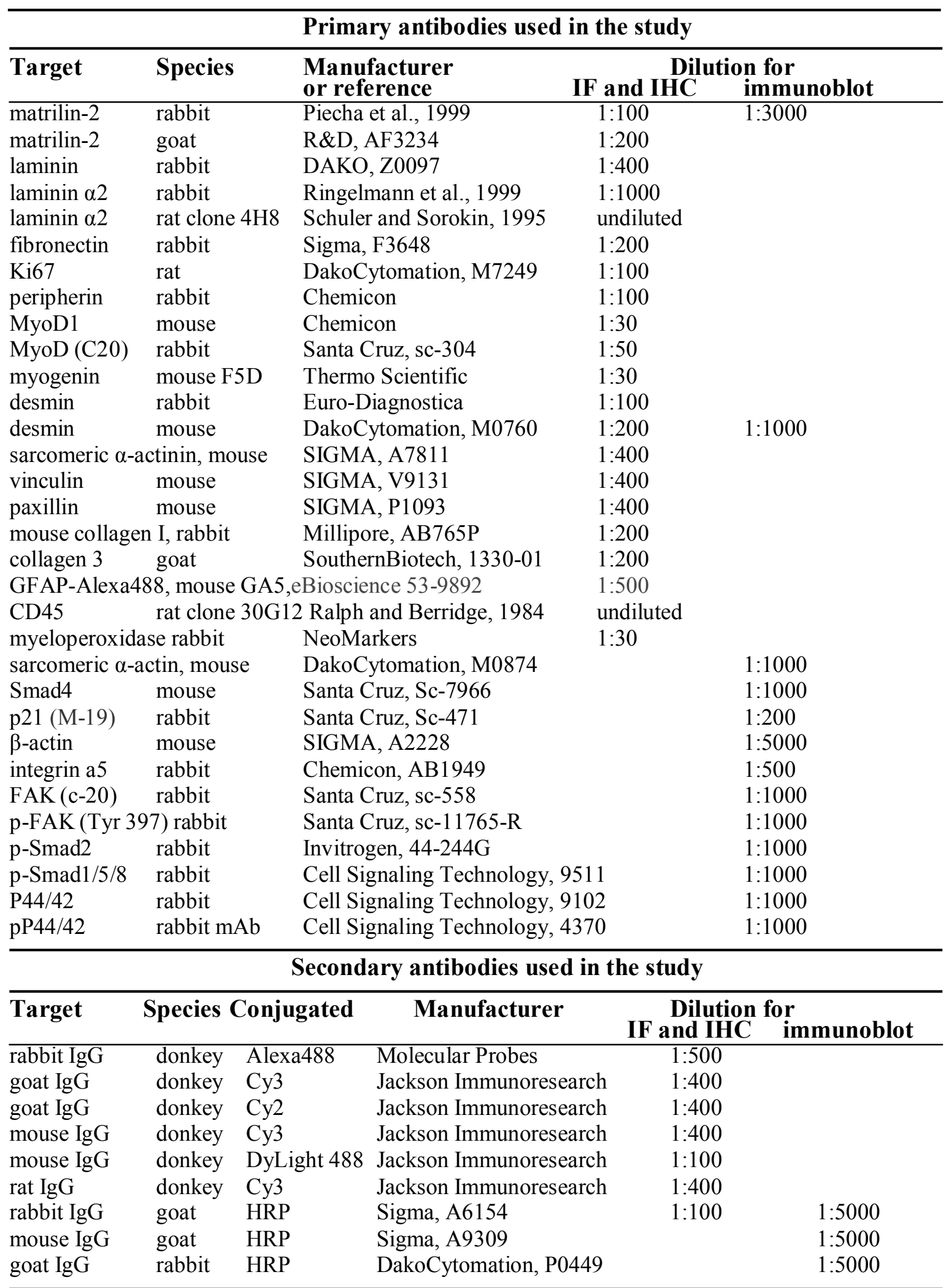

Ralph SJ, Berridge MV (1984) J. Immunol. 132:2510-2514 
Table S2. Primers used for amplification of hybridization probes and QRT-PCR

\begin{tabular}{|c|c|c|c|}
\hline Symbol & Acc. No. & Forward sequence & Reverse sequence \\
\hline Matn2 ${ }^{a}$ & XM 216941 & cctaccccaacggcataca & tgtgtgaacagtggcgaatc \\
\hline MyoD $^{a}$ & NM_176079 & ggttgagcgagaagcagga & gtagtaggcggcgtcgtag \\
\hline Myog $^{a}$ & NM_017115 & gacctgatggagctgtat & agacaatctcagttgggc \\
\hline Gapdh $^{\mathrm{a}}$ & NR_033630 & ccagccccagcatcaaaggt & caactttggcatcgtggaag \\
\hline Matn $2^{b}$ & $\underline{\text { XM } 216941}$ & gaggtggagagggctgtcaag & gcaatgttgagggcatattgg \\
\hline MyoD $^{b}$ & NM_176079 & ggacagccggtgtgcatt & cactccggaaccccaacag \\
\hline Myog $^{b}$ & NM_017115 & ggagaagcgcaggctcaag & ttgagcagggtgctcctctt \\
\hline $\mathrm{Fak}^{\mathrm{b}}$ & NM 013081 & agtgacgtgtggatgtttgc & atccgttcttcttgctgcac \\
\hline Matn2 ${ }^{\mathrm{c}}$ & NM_016762 & gaggtggagagggctgtcaag & gcaatgttgagggcatattgg \\
\hline Matn2 (ex1 ex2) ${ }^{c}$ & NM_016762 & ctgctccectgtctctcttc & cccaccaacatcttctccat \\
\hline MyoD $^{c}$ & M84918 & cgacaccgectactacagtg & tatgctggacaggcagtcg \\
\hline Myog $^{\mathrm{c}}$ & NM_031189 & cettgctcagctccetca & tgggagttgcattcactgg \\
\hline Myh1 $^{\mathrm{c}}$ & NM_030679 & aatcaaaggtcaaggcctacaa & gaatttggecaggttgacat \\
\hline $\operatorname{Trf} 3^{c}$ & AY457924 & tcatctttagctctgggaaagtg & cagccgagactcctcttcac \\
\hline $\mathrm{Taf}^{\mathrm{c}}$ & NM_027748 & ctgccatcggtactctgaact & agttcatgcagattaactcccata \\
\hline $\mathrm{p} 21^{\mathrm{c}}$ & NM_007669 & tccacagcgatatccagaca & ggacatcaccaggattggac \\
\hline $\operatorname{Mstn}^{\mathrm{c}}$ & NM_010834 & tggccatgatcttgctgtaa & ccttgacttctaaaaagggattca \\
\hline $\mathrm{p} 53^{\mathrm{c}}$ & NM_011640 & acgcttctccgaagactgg & agggagctcgaggctgata \\
\hline Lama $2^{c}$ & NM_008481 & tcaaccatgtgcttgtcctc & caatacacaagaggggctgaa \\
\hline Colba ${ }^{c}$ & NM_009933 & gacatccagggctccaaa & aggtgtcgagcacgaagaat \\
\hline $\mathrm{Sdc} 4^{\mathrm{c}}$ & NM_011521 & cccttccetgaagtgattga & agttccttgggetctgagg \\
\hline $\mathrm{Fn}^{\mathrm{c}}$ & NM_010233 & cggagagagtgcccctacta & cgatattggtgaatcgcaga \\
\hline Colla $^{c}$ & NM_007742 & catgttcagctttgtggacct & gcagctgacttcagggatgt \\
\hline $\mathrm{Fak}^{\mathrm{c}}$ & AB030035 & agtgacgtgtggatgtttgc & atccgttcttcttgctgcac \\
\hline $\operatorname{Itga} 5^{c}$ & NM_008402 & ggtgtggatcgagctgtctt & caaggccagcatttacagtg \\
\hline$N f i a^{c}$ & NM_010905 & ggaactcgatttatatttggcatac & ctggctgggactttcagatt \\
\hline $\mathrm{Nfib}^{\mathrm{c}}$ & NM_008687 & ccggaatacctggagtcg & gaaatggcaacggtgagg \\
\hline $\mathrm{Nfic}^{\mathrm{c}}$ & NM_026756 & catcgcggtacacagtgg & ggccgtatgggggaagta \\
\hline Nfix ${ }^{c}$ & NM_001081981 & tgactcctccatcaccttca & gatccgatgctgacaaacc \\
\hline $\mathrm{Eno}^{\mathrm{c}}$ & X62667.1 & ctttgcacccaacatcctg & gcctggatggctgtctttag \\
\hline $\mathrm{Ckm}^{\mathrm{c}}$ & NM_007710.2 & cagcacagacagacactcagg & gaacttgttgtgggtgttgc \\
\hline $\operatorname{Rps} 18^{\mathrm{b}, \mathrm{c}}$ & NM_011296 & tttgcgagtactcaacaccaa & ttcctcaacaccacatgagc \\
\hline $\mathrm{Hprt}^{\mathrm{b}, \mathrm{c}}$ & NM_013556 & tcctcctcagaccgctttt & cctggttcatcatcgctaatc \\
\hline CycloAb ${ }^{b, c}$ & NM_008907 & cacaaacggttcccagtttt & ttcccaaagaccacatgctt \\
\hline Matn2 & NM_016762.2 & 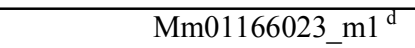 & \\
\hline MyoD1 & NM_010866.2 & Mm00440387_m1 ${ }^{\mathrm{d}}$ & \\
\hline Myog & NM_031189.2 & Mm00446194_m1 ${ }^{\mathrm{d}}$ & \\
\hline $\mathrm{p} 21$ & NM_007669.4 & Mm01303209_m1 ${ }^{\mathrm{d}}$ & \\
\hline Myh1 & NM_030679.1 & Mm01332489_m1 ${ }^{\mathrm{d}}$ & \\
\hline Mstn & NM_010834.2 & Mm00440328_m1 ${ }^{\mathrm{d}}$ & \\
\hline Nfia & NM_001122952.1 & Mm00447981_m1 ${ }^{\mathrm{d}}$ & \\
\hline Nfix & NM_001081982.1 & Mm00477796_m1 ${ }^{\mathrm{d}}$ & \\
\hline Hprt & NM_013556.2 & $\mathrm{Mm} 00446968 \mathrm{~m} 1^{\mathrm{d}}$ & \\
\hline
\end{tabular}

\footnotetext{
${ }^{\text {a }}$ Primers used for amplification of cDNA probes in Northern hybridization

${ }^{\mathrm{b}}$ Primers used in SYBR green protocol for rat samples

${ }^{\mathrm{c}}$ Primers used in SYBR green protocol for mouse samples

${ }^{\mathrm{d}}$ Applied Biosystems TaqMan probe sets
} 